\title{
Effects of exhumation kinematics and topographic evolution on detrital thermochronometer data
}

\author{
D. M. Whipp Jr., ${ }^{1,2,3}$ T. A. Ehlers, ${ }^{1,4}$ J. Braun, ${ }^{2,5}$ and C. D. Spath ${ }^{1}$ \\ Received 11 November 2008; revised 11 June 2009; accepted 10 August 2009; published 8 December 2009.
}

[1] Detrital thermochronometer data collected from modern rivers or sedimentary basins have the potential to record the evolution of topographic relief, fault kinematics and erosion within drainage basins. However, few studies have addressed the effects of these different factors on detrital thermochronometer age distributions. Here we use transient 3-D thermokinematic and landform evolution models to simulate the effects of time-varying topography and fault kinematics on the thermal field through which detrital samples cool. Cooling-rate-dependent apatite (U-Th)/He (AHe), zircon fission track and muscovite ${ }^{40} \mathrm{Ar} /{ }^{39} \mathrm{Ar}$ (MAr) grain age distributions are predicted for samples collected from modern river and basin sediments. These distributions are interpreted to determine the sensitivity of different thermochronometer systems to denudation and deformation histories in drainage basins of varying size. We find that detrital thermochronometers in rapidly eroding regions have a strong sensitivity to the kinematics of exhumation, but lack sensitivity to changes in topographic relief under most conditions. In addition, we find potential for significant overestimation of denudation rates derived from conventional 1-D age-elevation relationships as compared to 3-D model-prescribed rates. At rapid $(\sim 2.5 \mathrm{~mm} / \mathrm{y})$ model-prescribed denudation rates, 1-D techniques predict rates that are $\sim 5$ and $\sim 2$ times greater than the 3-D model rate for the AHe and MAr systems, respectively. In models that explore age distributions in foreland basin sediments, we confirm that the lag time concept is a useful and reliable means for identifying denudation rate changes as no significant change in lag time occurs for changing topographic relief scenarios.

Citation: Whipp, D. M., Jr., T. A. Ehlers, J. Braun, and C. D. Spath (2009), Effects of exhumation kinematics and topographic evolution on detrital thermochronometer data, J. Geophys. Res., 114, F04021, doi:10.1029/2008JF001195.

\section{Introduction}

[2] Detrital geochronology techniques can provide catchment-wide denudation histories [e.g., Cerveny et al., 1988; Copeland and Harrison, 1990; Renne et al., 1990; Brandon and Vance, 1992; Garver and Brandon, 1994a; Spiegel et al., 2000; Bernet et al., 2001; Schaller et al., 2001; Ruhl and Hodges, 2005; Hodges et al., 2005; Brewer et al., 2006; van der Beek et al., 2006; Schaller and Ehlers, 2006; Stock et al., 2006; Vermeesch, 2007] and have the potential to record temporal variations in both tectonics and landscape evolution [e.g., Stock and Montgomery, 1996; Brewer et al., 2003; Bernet et al., 2006; Szulc et al., 2006; Rahl et al., 2007; Reiners, 2007]. However, similar to bedrock thermochronometer data, the interpretation of detrital

\footnotetext{
${ }^{1}$ Department of Geological Sciences, University of Michigan, Ann Arbor, Michigan, USA.

${ }^{2}$ Géosciences Rennes, Université de Rennes 1, Rennes, France.

${ }^{3}$ Now at Department of Oceanography, Dalhousie University, Halifax, Nova Scotia, Canada.

${ }^{4}$ Now at Institut für Geowissenschaften, Universität Tübingen, Tübingen, Germany.

${ }^{5}$ Now at Laboratoire de Géodynamique des Chaînes Alpines, Université Joseph Fourier, Grenoble, France.
}

Copyright 2009 by the American Geophysical Union. 0148-0227/09/2008JF001195 thermochronometer data can be complicated by a number of factors, such as evolving topography, erosion, faulting, groundwater flow, rock thermophysical properties, paleowildfires, and the quantity and distribution of dateable minerals within the catchment [e.g., Brewer et al., 2003; Ehlers and Farley, 2003; Amidon et al., 2005; Ehlers, 2005; Brewer and Burbank, 2006; Brewer et al., 2006; Ehlers et al., 2006; Densmore et al., 2007; Reiners et al., 2007; Whipp et al., 2007; Whipp and Ehlers, 2007]. At present, their relative influence is unclear, limiting the potential power of detrital thermochronometer data. The goal of this paper is to quantify the impact of various exhumation, faulting and topographic evolution scenarios on predicted detrital thermochronometer age distributions to determine the expected sensitivity of detrital data sets to these factors.

[3] Previous studies have explored the effects of crustal thermal processes on bedrock thermochronometer ages. Denudation and steady state surface topography were shown to significantly affect the subsurface thermal field and lowtemperature thermochronometers in mountainous regions using two-dimensional (2-D) thermal models [Stüwe et al., 1994; Mancktelow and Grasemann, 1997]. Improving on the strictly vertical rock advection simulated in those studies, Henry et al. [1997], Stüwe and Hintermüller [2000] and Batt and Brandon [2002] showed how a lateral velocity component to particle transport changes predicted bedrock thermo- 


\section{Constant erosion rate and age-elevation relationship}

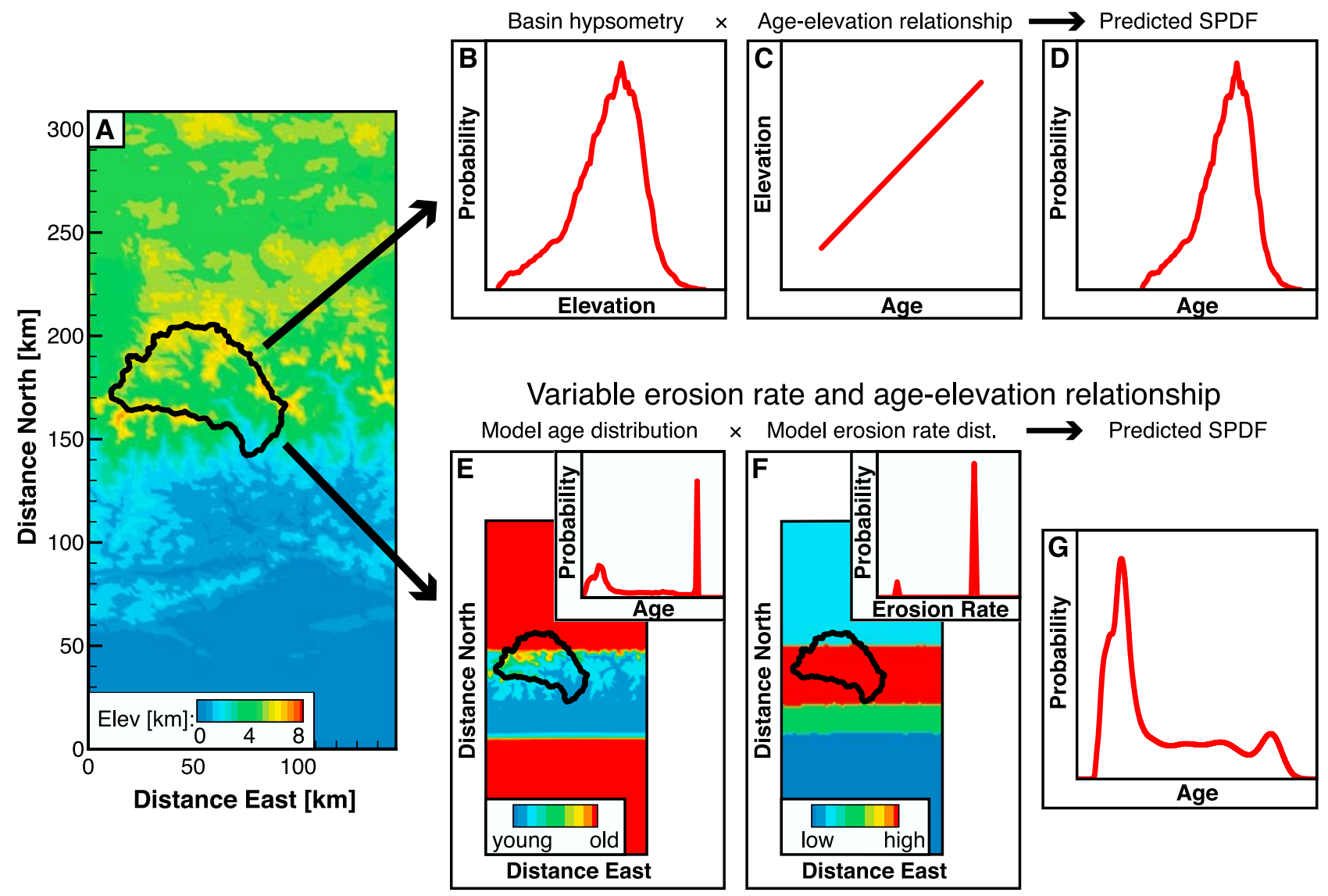

Figure 1. Comparison of methods used to produce predicted detrital age distributions in previous works and in this study. (a) Contoured model topography from the central Nepalese Himalaya with the catchment boundary (black outline) used for age distribution prediction. (b-d) Summary of previous detrital thermochronology modeling studies [e.g., Brewer et al., 2003; Ruhl and Hodges, 2005; Stock et al., 2006; Vermeesch, 2007], where a basin hypsometry (Figure 1b) was convolved with a fixed bedrock age-elevation relationship (Figure 1c) to generate a predicted age distribution assuming spatially uniform erosion. This is referred to as the 1-D approach in the text. (e-g) The methodology used in this study where the contoured predicted ages (Figure 1e), surface denudation rates (Figure 1f), and their distributions (insets in Figures 1e and 1f) are spatially variable in the third dimension. The age and denudation rate distributions are combined to generate the predicted age distribution (Figure $1 \mathrm{~g}$ ).

chronometer ages. Braun [2002] also used 2-D thermal modeling to show that changes in topographic relief in orogens can have a strong influence on the relationship between thermochronometer age and sample elevation, in some cases even inverting that relationship. In addition, a number of recent studies have further extended our understanding of how bedrock thermochronometers are affected by two- and three-dimensional (3-D) variations in exhumation kinematics, topographic evolution and rock thermal properties [e.g., Braun, 2003; Ehlers and Farley, 2003; Bollinger et al., 2006; Brewer and Burbank, 2006; Ehlers et al., 2006; Densmore et al., 2007; Whipp et al., 2007; Huntington et al., 2007].

[4] The extension of the above methods into detrital applications that simulate grain age distributions in modern rivers or sedimentary basins has lagged behind the bedrock equivalents. In one of the first modeling applications, Brewer et al. [2003] used a 2-D thermal model to predict a relationship between bedrock cooling ages and elevation that was convolved with drainage basin elevation hypsometries to generate predicted catchment age distributions from modern river sediments (e.g., Figures $1 \mathrm{a}-1 \mathrm{~d}$ ). Using a similar approach, Ruhl and Hodges [2005] replaced the model-generated bedrock age-elevation relationship with an observed relationship and applied their model to determine catchment-wide denudation rates and test assumptions about spatial variations in catchment erosion. Brewer and Burbank [2006] improved on the use of a linear bedrock age-elevation relationship by implementing a more complex 2-D thrust fault kinematic model. Their model was extended laterally across the area of interest to allow for catchment subsampling and comparison to data from modern river sediment. Most recently, Rahl et al. [2007] used a onedimensional (1-D) transient thermal model to predict detrital ages in both modern river sediment and foreland basin deposits resulting from a variety of temporally variable denudation histories. The power of their model is the ability 


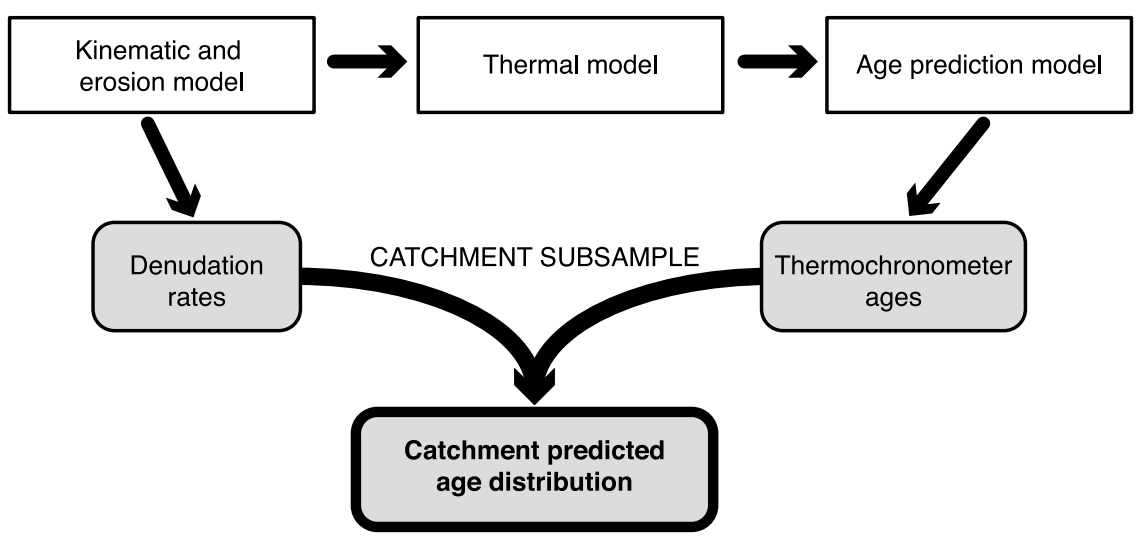

Figure 2. Flow diagram showing the modeling procedure used in this study. The coupled thermokinematic model controls the predicted ages at the model surface. Denudation rates and ages within the catchment of interest are subsampled and combined to produce the model-predicted age distribution.

to better quantify temporal trends in denudation generated from cooling age distributions preserved in foreland basins.

[5] Although the approaches used in previous studies (e.g., Figures $1 \mathrm{a}-1 \mathrm{~d}$ ) have advanced our understanding of detrital thermochronometer data, it remains unclear how sensitive detrital data are to long-term spatial and temporal variations in erosion or tectonics at the scale of an individual drainage basin (e.g., Figures $1 \mathrm{a}$ and $1 \mathrm{e}-1 \mathrm{~g}$ ). The utility of previous techniques is limited by the requirements that topography and the thermal field be in steady state, and the catchment denudation rates are spatially invariant. We complement previous studies by modeling the detrital record of various processes both in modern river and foreland basin sediment. We modified a 3-D thermokinematic numerical model [Braun, 2003] to predict grain age distributions from drainage basins as a function of topographic evolution, exhumation kinematics and rock thermophysical properties. The primary goal of this study is to characterize the effects of rock transport kinematics and evolving topography on predicted age distributions. In the models used here, we clarify the processes that can be detected in detrital thermochronometer data sets with and without the use of numerical models to aid in data interpretation. Our secondary goal is to assess the magnitude of error in basin-wide denudation rate estimates calculated using 1-D age-elevation relationships.

\section{Numerical Modeling Approach}

[6] We utilize a modified version of the thermokinematic numerical model Pecube [Braun, 2003] to simulate a number of processes potentially recorded in detrital thermochronometer data. New routines were added to Pecube to predict grain age distributions for various thermochronometer systems in drainage basins across a landscape (Figures 1a and $1 \mathrm{e}-1 \mathrm{~g}$ ). The model consists of three components: (1) A kinematic and erosion model, (2) a thermal model and (3) an age prediction model (Figure 2). The kinematic model is coupled to the thermal model and used to track exhumation and cooling histories for thermochronometer age prediction. Below, we provide detail on the numerical model setup and free parameters. Discussion of the numerical model results can be found in Section 3.

\subsection{Kinematic Model}

[7] The kinematic model is used to simulate rock transport resulting from processes such as erosional exhumation and faulting. In addressing the sensitivity of detrital thermochronometer data to these processes, we focus on three different kinematic scenarios. The first scenario is that of vertical transport of rock as the overlying material is eroded. The second case is similar to the vertical case, but with an additional lateral component to the velocity field. This scenario, although somewhat simplified, is designed to incorporate the first order thermal effects of lateral transport of rock, such as in an active convergent orogen. The final scenario is referred to as the thrust scenario and uses the most complicated kinematics. In this scenario, the velocity field is intended to simulate the effects of rock transport in a fold and thrust belt on the thermal field (e.g., Figure 3). This scenario includes multiple active thrust faults, frictional shear heating on those faults and partitioning of zones of variable thermophysical material properties by the faults. Although relevant information on the thrust scenario is provided below, a detailed discussion can be found in Appendix A.

\subsubsection{Vertical Kinematic Scenario}

[8] In cases where the model topography does not change with time, the vertical kinematic scenario yields a spatially uniform denudation rate. In this study, we focus on kinematic model variants that produce denudation rates typical of those observed in active orogens $(0.5-2.5 \mathrm{~mm} / \mathrm{y})$. For this kinematic scenario, the prescribed magnitude of the vertical velocity is the only free parameter and is exactly balanced by the denudation rate such that the topography is in steady state. Thus, the range of input velocities in the vertical kinematic scenario is $0.5-2.5 \mathrm{~mm} / \mathrm{y}$.

\subsubsection{Lateral Kinematic Scenario}

[9] Similar to the vertical kinematic scenario, denudation in the lateral kinematic scenario is spatially uniform when the model topography does not change. In this case, the denudation rate exactly compensates the vertical component of the velocity field. The desired range of denudation rates is generated by varying two free parameters: The lateral component of the velocity field and the angle of material transport with respect to horizontal. This is analogous to the 


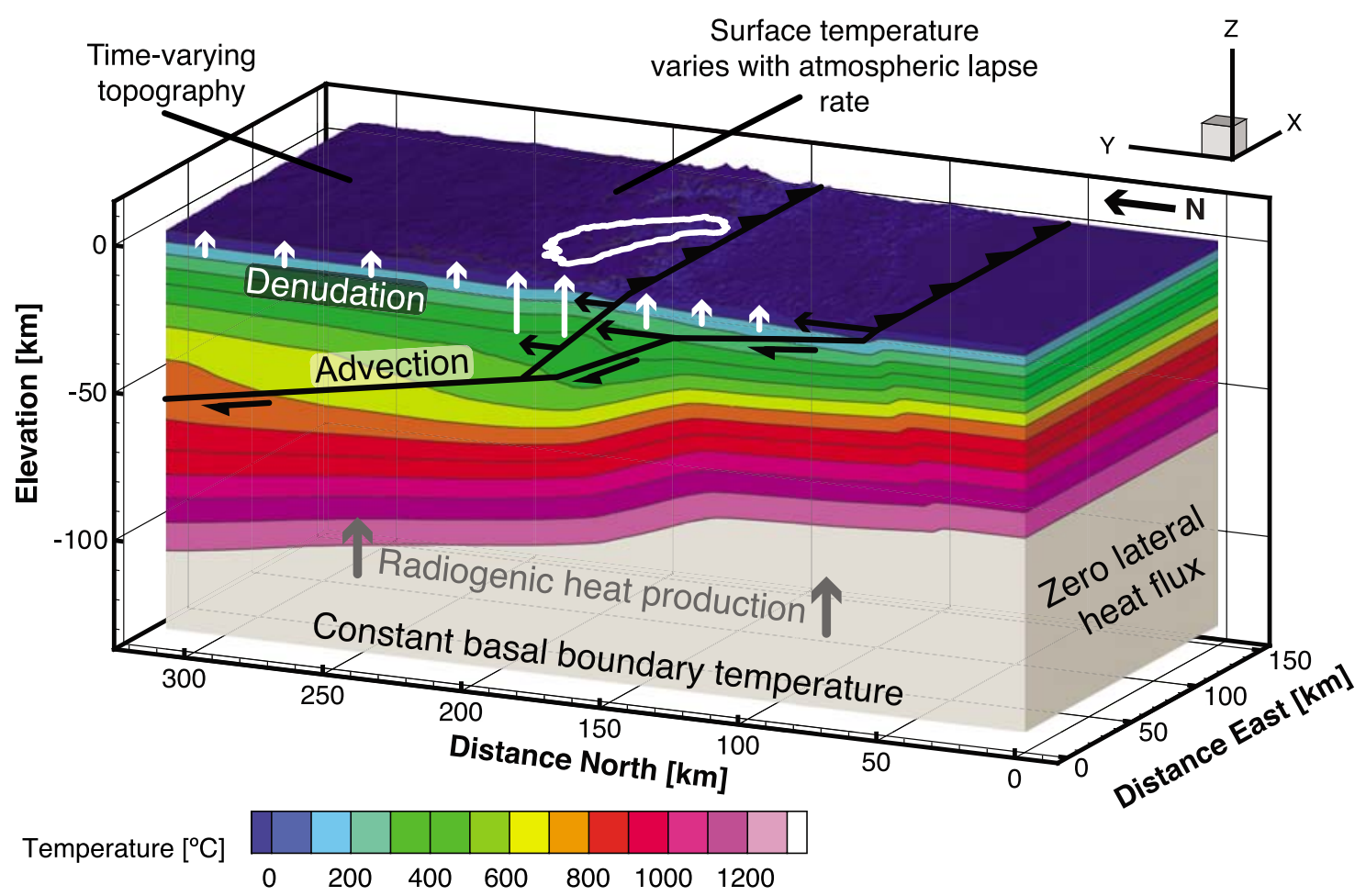

Figure 3. Example 3-D thermal model showing thermal model components and boundary conditions. The thrust kinematic model is illustrated here, where the faults (thick black lines) are advected in the positive y direction with time as underthrusting occurs. Temperature contours (thin black lines) show the thermal perturbation resulting from the thrust kinematics. Denudation (white arrows) balances the flux of material through the model surface and is spatially variable depending on the dip angle of the underlying fault. Fault positions with time dictate the denudation rates within the catchment of interest (white outline).

lateral drainage migration model of Stüwe and Hintermüller [2000], and thus requires that all hillslope angles in the model domain are shallower than the material transport angle. We assume a uniform angle with respect to horizontal of $40^{\circ}$, which exceeds the hillslope angles across the model topography and generates denudation rates of $0.5-2.5 \mathrm{~mm} / \mathrm{y}$ with an input convergence rate range of $\sim 0.8-3.9 \mathrm{~mm} / \mathrm{y}$.

\subsubsection{Thrust Kinematic Scenario}

[10] The thrust model features two active faults with variable dip angle near the surface and at depth, leading to spatially variable denudation rates. Below we provide a brief overview of this kinematic scenario and note that a detailed description about the thrust kinematic scenario and chosen reference frame can be found in Appendix A. The structural geometry is based on the central Nepalese Himalaya with two important structures in the model area: A thrust fault that intersects the model upper surface and the basal décollement from which that fault splays (Figure 3). The interior thrust fault has a dip angle of $40^{\circ}$ and splays off the basal décollement dipping at $10^{\circ}$ at a depth of $\sim 25 \mathrm{~km}$. In the simulations using the thrust kinematic model, the surface topography is fixed and the faults are advected laterally with time to generate vertical particle pathways for material in the thrust fault hanging walls. This reference frame is similar to the horizontal landscape advection case of Herman et al. [2007]. The resulting geometry is such that most of the basin area for basins used in this study is within the steeply dipping portion of the interior thrust hanging wall and a small fraction is within the shallower section. This geometry yields denudation rates within the steeply dipping section of the hanging wall that are $\sim 3.7$ times faster than rates in the shallowly dipping section. An example of the denudation rate distribution can be seen in Figure 1f, where the southern section of the outlined basin features a relatively high denudation rate and a small fraction of the northern region has a slower rate. This distribution of catchment denudation rates can also be viewed as a probability distribution, resulting in a large peak for the higher rate and a small peak at the slower rate. To generate the desired range of denudation rates, the thrust model requires input overthrusting rates of $\sim 1.2-6.0 \mathrm{~mm} / \mathrm{y}$ partitioned equally between the interior thrust and material in the hanging wall of the basal décollement. Total convergence across the model is fixed at $20 \mathrm{~mm} / \mathrm{y}$, so motion not assigned to overthrusting will be applied as underthrusting to the footwall of the basal décollement.

\subsection{Erosion Model}

[11] One of the unique and powerful features of Pecube is the simple implementation of complicated geometries including input of digital elevation models (DEMs) for surface topography and the ability to include temporal variations in surface topography. Topographic modification in Pecube is driven by two terms: A scaling factor that is multiplied by the surface elevations to scale the topographic relief, and an offset factor that shifts all of the surface elevations by a constant value. Both values are input at each model time step 
Table 1. Numerical Model Parameters

\begin{tabular}{|c|c|}
\hline Property/Parameter & Model Input Value \\
\hline \multicolumn{2}{|c|}{ Material Properties } \\
\hline Vertical model heat production & $0.8 \mu \mathrm{W} / \mathrm{m}^{3}$ \\
\hline Lateral model heat production & $0.8 \mu \mathrm{W} / \mathrm{m}^{3}$ \\
\hline Thrust model heat production & $0.5-1.9 \mu \mathrm{W} / \mathrm{m}^{3}$ \\
\hline Thermal conductivity & $2.75 \mathrm{~W} / \mathrm{m} \mathrm{K}$ \\
\hline Specific heat & $1000 \mathrm{~J} / \mathrm{kg} \mathrm{K}$ \\
\hline Density & $2700 \mathrm{~kg} / \mathrm{m}^{3}$ \\
\hline \multicolumn{2}{|c|}{ Numerical Parameters } \\
\hline Model domain & $150 \times 310 \times 130 \mathrm{~km}$ \\
\hline Horizontal node spacing & $\sim 0.95 \mathrm{~km}$ \\
\hline Vertical node spacing $(0-5 \mathrm{~km})$ & $\sim 0.95 \mathrm{~km}$ \\
\hline Vertical node spacing $(5-15 \mathrm{~km})$ & $\sim 2.85 \mathrm{~km}$ \\
\hline Vertical node spacing $(15-130 \mathrm{~km})$ & $\sim 8.55 \mathrm{~km}$ \\
\hline Vertical model denudation rate & $0.5-2.5 \mathrm{~mm} / \mathrm{y}$ \\
\hline Lateral model dip angle & $40^{\circ}$ \\
\hline Lateral model convergence rate & $0.8-3.9 \mathrm{~mm} / \mathrm{y}$ \\
\hline Thrust model convergence rate ${ }^{a}$ & $1.2-6.0 \mathrm{~mm} / \mathrm{y}$ \\
\hline Topographic scaling factor & $0.5-1$ \\
\hline Topographic offset factor & $0.068-4.061 \mathrm{~km}$ \\
\hline Surface temperature at sea level & $24^{\circ} \mathrm{C}$ \\
\hline Atmospheric lapse rate & $-6^{\circ} \mathrm{C} / \mathrm{km}$ \\
\hline Basal temperature & $1350^{\circ} \mathrm{C}$ \\
\hline Thermal model time step ${ }^{\mathrm{b}}$ & $\sim 0.05-0.25 \mathrm{My}$ \\
\hline Simulation time & $50 \mathrm{My}$ \\
\hline
\end{tabular}

and the combination of the two terms will morph the topography between the previous form and the current form over the given time step with no change in the planform drainage pattern. In section 3.3, we discuss model results using the combination of the two parameters to simulate a $50 \%$ increase in topographic relief across the entire model domain while maintaining either a constant valley bottom or peak elevation.

[12] The two relief change scenarios discussed above generate spatial variations in the denudation rate. For example, when the topography is fixed, a parcel of rock traveling vertically toward the model surface at $1 \mathrm{~mm} / \mathrm{y}$ would experience a denudation rate of $1 \mathrm{~mm} / \mathrm{y}$. However, in a case where the topographic relief is increasing about a fixed minimum (base level) elevation and the top surface of the model is moving upward with time, the denudation rate for a parcel of rock beneath a peak would be less than $1 \mathrm{~mm} / \mathrm{y}$. Thus, the effective denudation rate is simply the combination of the input background rate and the rate of change of the surface elevations, where lowering of the surface topography increases the effective denudation rate and raising the surface elevations has the opposite effect.

\subsection{Thermal Model}

[13] The kinematic and erosion models described above are coupled to the thermal model through the advection velocity in the transient advection-diffusion equation solved using Pecube [Carslaw and Jaeger, 1959; Braun, 2003],

$$
\begin{array}{r}
\rho c\left(\frac{\partial T}{\partial t}+v_{x} \frac{\partial T}{\partial x}+v_{y} \frac{\partial T}{\partial y}+v_{z} \frac{\partial T}{\partial z}\right)= \\
\frac{\partial}{\partial x} k \frac{\partial T}{\partial x}+\frac{\partial}{\partial y} k \frac{\partial T}{\partial y}+\frac{\partial}{\partial z} k \frac{\partial T}{\partial z}+\rho A
\end{array}
$$

where $\rho$ is rock density, $c$ is rock specific heat capacity, $T$ is temperature, $t$ is time, $x, y$ and $z$ are spatial coordinates, $v_{x}, v_{y}$, and $v_{z}$ are the advection velocity components from the kinematic model, $k$ is thermal conductivity and $A$ is volumetric radiogenic heat production. Equation 1 is formulated in the finite element method using the streamline upwind Petrov-Galerkin method for numerical stability [Brooks and Hughes, 1982]. The resulting equations are solved using constant temperature (Dirichlet) upper and lower boundary conditions and zero flux (Neumann) boundaries on the model sides, and a Gauss-Seidel iterative method with overrelaxation [Bathe, 1982]. The calculation output is the full 3-D thermal field for the given input model region (Figure 3).

[14] For the simulations presented here, we use a lithospheric block geometry that is $150 \times 310 \times 130 \mathrm{~km}(\mathrm{~L} \times$ $\mathrm{W} \times \mathrm{D}$ ) in size (Figure 3 ). The average $\mathrm{x}-\mathrm{y}$ node spacing in the finite element mesh is $\sim 950 \mathrm{~m}$. Although this study does not focus specifically on the Himalaya, we utilize a DEM from central Nepal for the surface topography as this region features high-relief topography typical of active orogens. The DEM-derived surface topography is from a Shuttle Radar Topography Mission DEM with a resolution of $\sim 90 \mathrm{~m}$ [Farr et al., 2007].

[15] In addition to the input kinematic scenario and topographic evolution, there are several thermal parameters in Pecube that affect the solution, but were not varied between simulations. As mentioned above, the finite element solution of Equation 1 uses constant temperature boundary conditions at the base and upper surface of the model. We use a lithospheric basal temperature of $1350^{\circ} \mathrm{C}$ at $130 \mathrm{~km}$ depth, similar to previous studies in large, hot orogens [e.g., Vanderhaeghe et al., 2003; Beaumont et al., 2004; Jamieson et al., 2004; Jiménez-Munt and Platt, 2006]. The upper surface temperature is $24^{\circ} \mathrm{C}$ at sea level and follows an atmospheric lapse rate of $6^{\circ} \mathrm{C}$ per $\mathrm{km}$ elevation increase, comparable to typical values used in high relief orogens [e.g., Ehlers and Farley, 2003; Fluteau, 2003; Huntington et al., 2007; Whipp et al., 2007]. Thermophysical material properties, such as thermal conductivity and specific heat capacity are spatially invariant in models using the vertical and lateral kinematic models. In the thrust model, the faults separate regions of distinct material properties, and thus the material properties listed above vary spatially depending on the location of the material relative to the faults. There is also an additional heat source in the thrust models resulting from frictional shear heating on the fault surfaces. Details on the spatial partitioning of material properties and shear heating in the thrust model can be found in Appendix A. In all of the models, the radiogenic heat production is constant from the surface down to $50 \mathrm{~km}$ depth and there is no radiogenic heat production below that depth. In all three scenarios, the thermophysical material property values are based on those used in previous models of the region [e.g., Huntington et al., 2007; Whipp et al., 2007]. Last, all of the transient thermal models use a time step calculated within Pecube [Braun, 2003] with a typical value of $\sim 0.05-0.25 \mathrm{My}$ over a simulation time of $50 \mathrm{My}$. A summary of the model input values can be found in Table 1.

[16] It should be noted that the model setup does not include the effects of groundwater flow on the crustal thermal field [e.g., Smith and Chapman, 1983; Forster and Smith, 1989; Person et al., 1995; Whipp and Ehlers, 2007]. Groundwater circulation tends to counteract the topographic pertur- 
bation of near-surface isotherms, as well as decrease the thermal gradient in the shallow crust, particularly beneath peaks. Previous work has shown that this effect can be quite significant for low-temperature thermochronometers [e.g., Whipp and Ehlers, 2007] and including the effects of groundwater flow when interpreting thermochronometer data would be important in areas with pervasive fluid flow. However, it is expected that the sensitivity to the model free parameters and general results we present below would not change with the inclusion of groundwater flow. In addition, as we do not aim to interpret collected thermochronometer data in this study, we have chosen not to simulate the effects of groundwater flow.

\subsection{Bedrock Thermochronometer Age Prediction Model}

[17] Cooling-rate-dependent thermochronometer ages are calculated in the model by tracking the exhumation pathway and cooling history of rocks exposed at the surface. Particle positions and temperatures for the surface nodes are calculated at each time step from the kinematic and thermal models. In addition to particles reaching the model surface at the end of the final time step ( $0 \mathrm{Ma})$, cooling ages can be predicted for surface nodes at specified times during the model run. This added functionality allows for the simulation of temporal evolution of the ages at the surface as the model runs.

[18] Model-predicted thermal histories are used to calculate apatite (U-Th)/He (AHe), apatite fission track (AFT), zircon (U-Th)/He (ZHe), zircon fission track (ZFT) and muscovite ${ }^{40} \mathrm{Ar} /{ }^{39} \mathrm{Ar}$ (MAr) thermochronometer ages using our modified version of Pecube [Braun, 2003; Braun et al., 2006]. Kinetic parameters used for (U-Th)/He age prediction include: (1) Durango apatite [Farley, 2000], (2) the apatite alpha radiation damage model of Shuster et al. [2006] and (3) the average zircon kinetics from Reiners et al. [2004]. AFT ages are predicted using the Crowley et al. [1991] kinetic parameters. ZFT and MAr ages are calculated based on the concepts of Dodson [1973] as implemented by Braun et al. [2006], with the kinetic parameters of Brandon et al. [1998] for ZFT, and Robbins [1972] and Hames and Bowring [1994] for MAr.

[19] For simplicity in the presentation of results, we focus on three systems that span a wide range of temperature sensitivities: Durango AHe, ZFT and MAr. These systems have effective closure temperatures [Dodson, 1973] of $\sim 67-83^{\circ} \mathrm{C}, \sim 232-256^{\circ} \mathrm{C}$ and $\sim 381-426^{\circ} \mathrm{C}$, respectively, for cooling rates of $10-100^{\circ} \mathrm{C} / \mathrm{My}$ [e.g., Ehlers et al., 2005; Reiners and Brandon, 2006]. Because the total model run time is $50 \mathrm{My}$, unreset cooling ages will have an age of $\sim 50$ Ma minus the time at which they reach the surface. In other words, an unreset age at the surface at $10 \mathrm{Ma}$ would be $\sim 40 \mathrm{Ma}$.

\subsection{Generation of Detrital Age Distributions}

[20] Bedrock thermochronometer ages at the model surface are used to calculate grain age distributions produced upstream of user-defined sample collection locations (e.g., Figure 2). The drainage basin boundary upstream of the detrital sample locations is determined using the D8 algorithm [O'Callaghan and Mark, 1984; Jenson and Domingue, 1988] to identify the bedrock age points that are within the basin. After extracting ages from the landscape, an age histogram is created, forming the raw age distribution. Next, the same points are probed in the model to generate the corresponding distribution of denudation rates. The individual denudation rates and matching raw ages are then convolved to generate a model probability density function $\left(\mathrm{PDF}_{m}\right)$ for each predicted age $\left(t_{m}\right)$ in the raw age distribution using an approach similar to that of Ruhl and Hodges [2005],

$$
\mathrm{PDF}_{m}=\frac{1}{\sigma_{t_{m}} \sqrt{2 \pi}} \exp \left[-\frac{1}{2}\left(\frac{t-t_{m}}{\sigma_{t_{m}}}\right)^{2}\right] \times v_{z}
$$

where $\sigma_{t_{m}}$ is the model one sigma age uncertainty, $t$ is the range of ages over which $\mathrm{PDF}_{m}$ is defined and $v_{z}$ is the corresponding denudation rate for the predicted age $t_{m}$. The difference between our $\mathrm{PDF}_{m}$ and that used by Ruhl and Hodges [2005] is the scaling of the $\mathrm{PDF}_{m}$ age peak magnitude by the denudation rate $\left(v_{z}\right)$. Denudation rate scaling is needed because regions with higher denudation rates will provide a larger quantity of datable grains within each catchment, assuming that the denudation rates at the final time step are representative of the long-term rates. In the cases we consider, the sample uncertainty $\left(\sigma_{t_{m}}\right)$ is a function of the model-predicted cooling ages and assumed to be $5 \%$ for AHe, $10 \%$ for ZFT and $4 \%$ for MAr to represent typical errors associated with grain age reproducibility and analytical uncertainties. Larger sample errors would generate broader age distributions with lower probability age peaks, although the peak ages should not change if the errors are a constant percentage. The basin-wide age distribution is created by summing the individual age $\mathrm{PDF}_{m} \mathrm{~s}$ to form a model synoptic probability density function $\left(\mathrm{SPDF}_{m}\right)$,

$$
\mathrm{SPDF}_{m}=\left[\frac{1}{n} \sum_{i=1}^{n} \mathrm{PDF}_{m}(i)\right] \times\left(\frac{1}{\overline{v_{z}}}\right)
$$

where $n$ is the number of predicted ages in the catchment and $\overline{v_{z}}$ is the mean denudation rate in that catchment. Division of the basin-wide age $\mathrm{SPDF}_{m}$ by the mean catchment denudation rate is necessary to ensure the area beneath the $\mathrm{SPDF}_{m}$ curve remains normalized to one for comparison of results between models. Thus, the detrital grain age prediction component of this study produces synthetic detrital distributions for user-defined sampling locations on the landscape.

[21] In addition, because cooling ages can be predicted at specified times in the past along with at $0 \mathrm{Ma}$, past detrital age distributions can be predicted. This allows for the simulation of ages that might be preserved in a foreland basin. When past age distributions are predicted, the stratigraphic age, or time at which the sampled ages reach the surface, is added to the predicted ages.

[22] The generation of the predicted detrital age distributions is based on several important assumptions. The generation of the raw age distribution assumes (1) every point in the catchment contributes target minerals, and (2) transport time and sediment storage are negligible [e.g., Bernet and Garver, 2005, and references therein]. Nonuniform sediment generation and sampling within the basin by 
mass-wasting processes or glacial erosion could potentially have a significant impact on the age distribution within a given catchment [e.g., Stock et al., 2006], however the magnitude of this effect is not known. Quantifying the potential influence of localized catchment erosion is the focus of ongoing work by the authors. Sediment storage in the catchment, such as ponding upstream of moraines, could have a similar magnitude effect to nonuniform erosional processes as the sampled sediment would be biased toward that downstream of any local basins. However, the magnitude of this potential factor is also unknown. In addition, generation of sediment at each point within the catchment assumes there is a uniform distribution of the target minerals within the catchment bedrock. Several recent studies have shown that mineral concentrations can vary by many orders of magnitude within large catchments [e.g., Brewer et al., 2003; Amidon et al., 2005; Brewer et al., 2006] and nonuniform mineral concentrations would clearly generate a sampling bias. The effect of this bias is not clear for the model results presented below, however a sampling bias would likely shift the peak age within the catchment age range and may decrease the width of the sample SPDF. This effect could be minimized by sampling in regions that experienced rapid cooling as the range of detrital ages in the catchment would be relatively small, or by collection of tributary and trunk stream samples to ensure the sampling bias is considered [e.g., Brewer et al., 2006]. Assuming no localized sediment generation or storage, the effect of transport time is likely to be small. The time between a sample cooling below its effective closure temperature and reaching the surface would be much greater than the expected transport time within a fluvial system, particularly in high-relief active orogens [e.g., Bernet and Garver, 2005; Hodges et al., 2005]. Last, for the generation of detrital ages that could be preserved in basin stratigraphy, it is assumed that the basin geometry does not change through time and that deposition is proximal to the basin outlet.

\section{Results}

[23] In the following, we identify possible diagnostic signatures of processes such as changes in denudation rate, fault activity and topographic relief in thermochronometer grain age distributions. Our results focus on the AHe, ZFT and MAr thermochronometer system responses to each process. For these systems, we present results assuming every point within the catchment contributes target minerals and was dated, as discussed in the previous section. In reality, we recognize that this is an impossible task and even dating the 50-100 grains needed to characterize the cooling history of an entire basin is an arduous task. In particular, because of the compositional and geometric restrictions on datable mineral grains, the AHe system may present difficulty in generating a detrital data set capable of recording the trends seen in the results we present. Although highquality detrital AHe data can be generated [e.g., Stock et al., 2006], some of the predicted age differences may be difficult to resolve in real-world data. Below, we present results for reference to future studies with the hope that technological and scientific advancements will continue to increase sample throughput and the range of datable materials, facilitating the continued growth of detrital methods.
With the exception of Section 3.4, that explores the effect of varying the drainage basin size, all results in this section are from a single drainage basin in the Nepalese Himalaya with a drainage area of $\sim 2775 \mathrm{~km}^{2}$ and $7164 \mathrm{~m}$ of topographic relief. It is worth noting that the topographic relief within the catchment of interest is extreme and the effects we discuss below may be smaller in catchments with less relief.

\subsection{Effects of Changing Denudation Rates 3.1.1. A Reference Scenario: Time-Invariant Denudation Rates}

[24] The simplest scenario that we explore is the effect of different time-invariant denudation rates on detrital thermochronometer ages. This effect and has been addressed by a number of previous studies [e.g., Garver et al., 1999; Brewer et al., 2003] and the results here are provided mainly for comparison with those presented in the following sections. For each of the models shown here, the vertical kinematic scenario is used and the input vertical velocity magnitude is the only free parameter. Denudation rates of $0.5,1.0$ or $2.5 \mathrm{~mm} / \mathrm{y}$ are explored (Figure $4 \mathrm{a}$ ). In these models, the surface topography does not change with time such that the vertical velocity is equivalent to the denudation rate.

[25] The primary differences for the model denudation rates between 0.5 and $2.5 \mathrm{~mm} / \mathrm{y}$ are a shift toward younger peak ages and a smaller age range in the catchment age distributions for each thermochronometer system. In the case of the AHe system, the peak age at a rate of $2.5 \mathrm{~mm} / \mathrm{y}$ is $\sim 11$ times younger than that using a rate of $0.5 \mathrm{~mm} / \mathrm{y}$ (Figure 4b). For the ZFT and MAr systems the peak ages are $\sim 10$ and $\sim 11$ times younger, respectively, for the same difference in denudation rate (Figures $4 \mathrm{c}$ and $4 \mathrm{~d}$ ). The denudation rate of $2.5 \mathrm{~mm} / \mathrm{y}$ also results in age ranges (i.e., widths of each age distribution) that are $\sim 9, \sim 9$ and $\sim 8$ times smaller for the AHe, ZFT and MAr thermochronometers, respectively (Figures $4 \mathrm{~b}-4 \mathrm{~d}$ ). The importance of the age range will be discussed in detail in Section 4.1, but note that we define the age range to be that which encompasses $99 \%$ of the area beneath the predicted $\mathrm{SPDF}_{m}$ curves, similar to Ruhl and Hodges [2005].

\subsubsection{Transient Variations in Denudation Rate}

[26] The effect of an acceleration in denudation rate is explored using a vertical kinematic field and input denudation rates of either 0.5 or $2.5 \mathrm{~mm} / \mathrm{y}$. The free parameter in this case is the time at which an instantaneous acceleration in denudation rate occurs, either at 10 or $2 \mathrm{Ma}$. Results are compared to models from the previous section with time invariant rates of either 0.5 or $2.5 \mathrm{~mm} / \mathrm{y}$ (Figure $5 \mathrm{a}$ ). The surface topography does not change with time. Again, as this effect has been previously discussed [e.g., Garver and Brandon, 1994b; Garver et al., 1999; Bernet et al., 2001; Bernet and Garver, 2005], we present a brief review of the results and will return to discuss this idea in detail in Section 4.2.

[27] The primary signal of an acceleration in denudation is a shift toward a younger peak age, particularly for an earlier acceleration and lower temperature thermochronometer. For denudation rate changes at 2 and $10 \mathrm{Ma}$, AHe peak ages are $\sim 6$ and $\sim 8$ times younger, respectively, than those generated by a constant rate of $0.5 \mathrm{~mm} / \mathrm{y}$ (Figure $5 \mathrm{~b}$ ). A comparison to ZFT peak ages, which are $\sim 3$ and $\sim 8$ times younger, and MAr peak ages, which are $\sim 1.5$ and $\sim 8$ times 

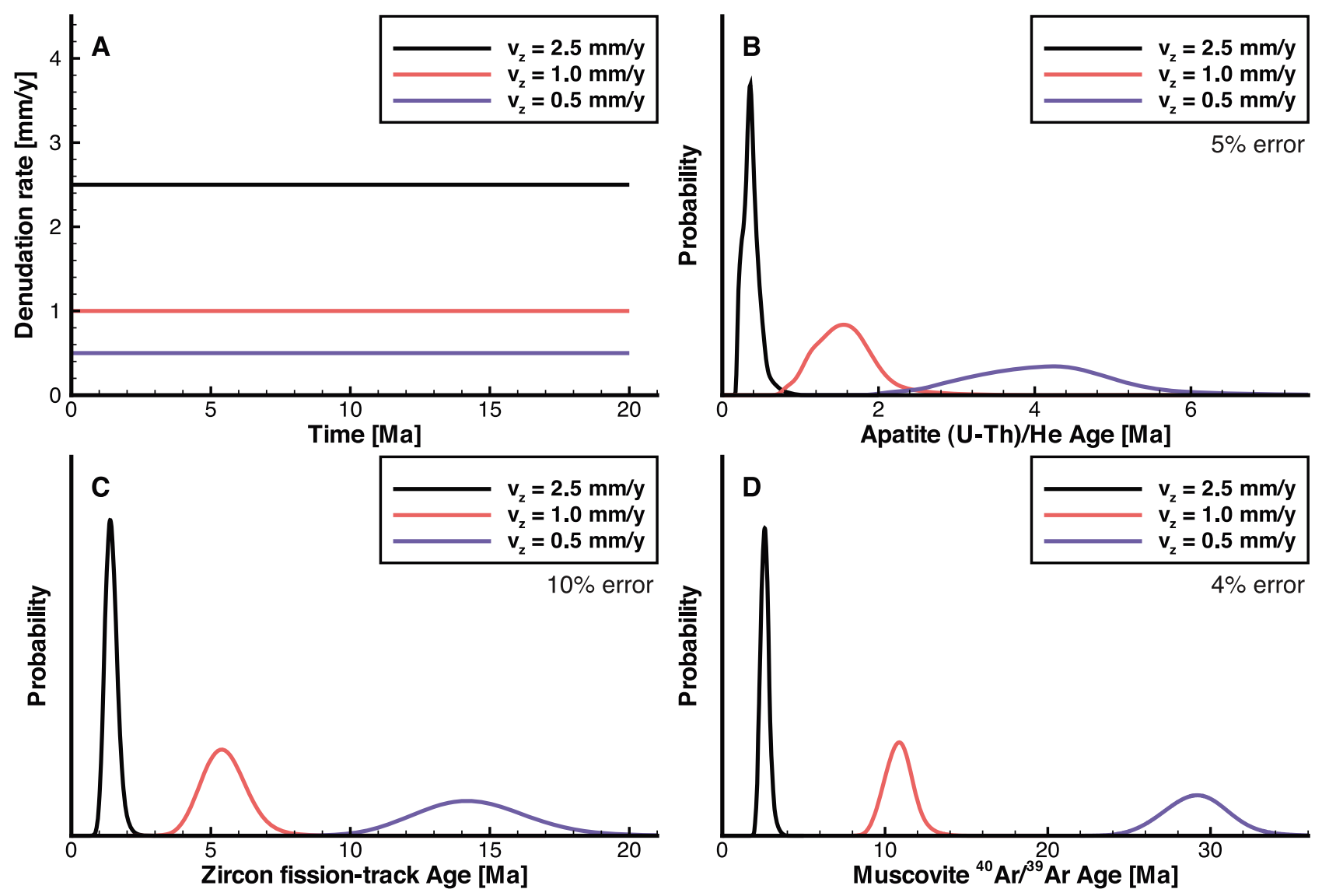

Figure 4. Effect of variable magnitude denudation rates on predicted age distributions. (a) Timeinvariant denudation rates of 2.5 (black), 1.0 (red), and $0.5 \mathrm{~mm} / \mathrm{y}$ (blue) are used with the vertical kinematic scenario to predict (b) AHe, (c) ZFT, and (d) MAr age distributions. The listed percent error is the $1 \sigma$ uncertainty used in generating the predicted $\mathrm{SPDF}_{m}$ curves.

younger, for an acceleration at 2 and $10 \mathrm{Ma}$, respectively, shows that the higher temperature systems have not seen sufficient denudation to fully expose young ages across the catchment in 2 My (Figures 5c and 5d). Furthermore, as seen in the previous section, an increase in denudation rate tends to generate a decrease in the age range of the corresponding distribution.

[28] Effectively, these results show that higher temperature systems have a longer response time to perturbations in denudation rate [e.g., Ehlers et al., 2005; Reiners and Brandon, 2006; Rahl et al., 2007]. In addition, the magnitude of the peak age shift depends on the magnitude of rate change. Figure 6 expands on the results presented above to provide a general sense of the expected peak age shift for rate changes of various magnitudes and times for thermochronometer systems with different effective closure temperatures. The base rate of $0.5 \mathrm{~mm} / \mathrm{y}$ is increased by $0-$ $2 \mathrm{~mm} / \mathrm{y}$ at 2-20 Ma and peak ages are predicted for the AHe and MAr thermochronometer systems. As seen in the previous results, the AHe thermochronometer has a more rapid response and larger peak age shift relative to the MAr system. Furthermore, both thermochronometers show larger peak age shifts for greater magnitudes of rate change (Figure 6). For example, an increase in denudation rate from 0.5 to $1.5 \mathrm{~mm} / \mathrm{y}$ at $10 \mathrm{Ma}$ generates a peak age that is $\sim 4$ times younger than a constant $0.5 \mathrm{~mm} / \mathrm{y}$ model in the
AHe system (circle a in Figure 6). If the rate change magnitude is increased such that the rate changes from 0.5 to $2.5 \mathrm{~mm} / \mathrm{y}$, the resulting peak age is $\sim 8$ times younger than the constant $0.5 \mathrm{~mm} / \mathrm{y}$ peak age (circle $\mathrm{b}$ in Figure 6 and Figure 5b). The MAr system behaves much like the AHe system, with peak ages that are $\sim 3$ and $\sim 8$ times younger for denudation rate increases of 1.0 and $2.0 \mathrm{~mm} / \mathrm{y}$, respectively (circles $\mathrm{c}$ and $\mathrm{d}$ in Figure 6 and Figure 5d). However, it is important to note that, as above, a more recent rate change will result in a smaller peak age shift, particularly for higher temperature thermochronometers (Figure 6b). In summary, both high- and low-temperature thermochronometers are strongly sensitive to changes in denudation rate, however the AHe thermochronometer shows much less sensitivity to the timing of denudation rate change than the MAr system, provided there has been at least 2 My since the rate change.

\subsection{Effects of Exhumation Kinematics and Faulting}

[29] The kinematics of rock exhumation are an important influence on grain age distributions. Here we consider the effects of lateral transport of rock and faulting on age distributions. The only model free parameter in this section is the exhumation kinematic field and, as above, we compare the results from the lateral and thrust kinematic scenarios to models using the vertical kinematic scenario (Figure 7a). 

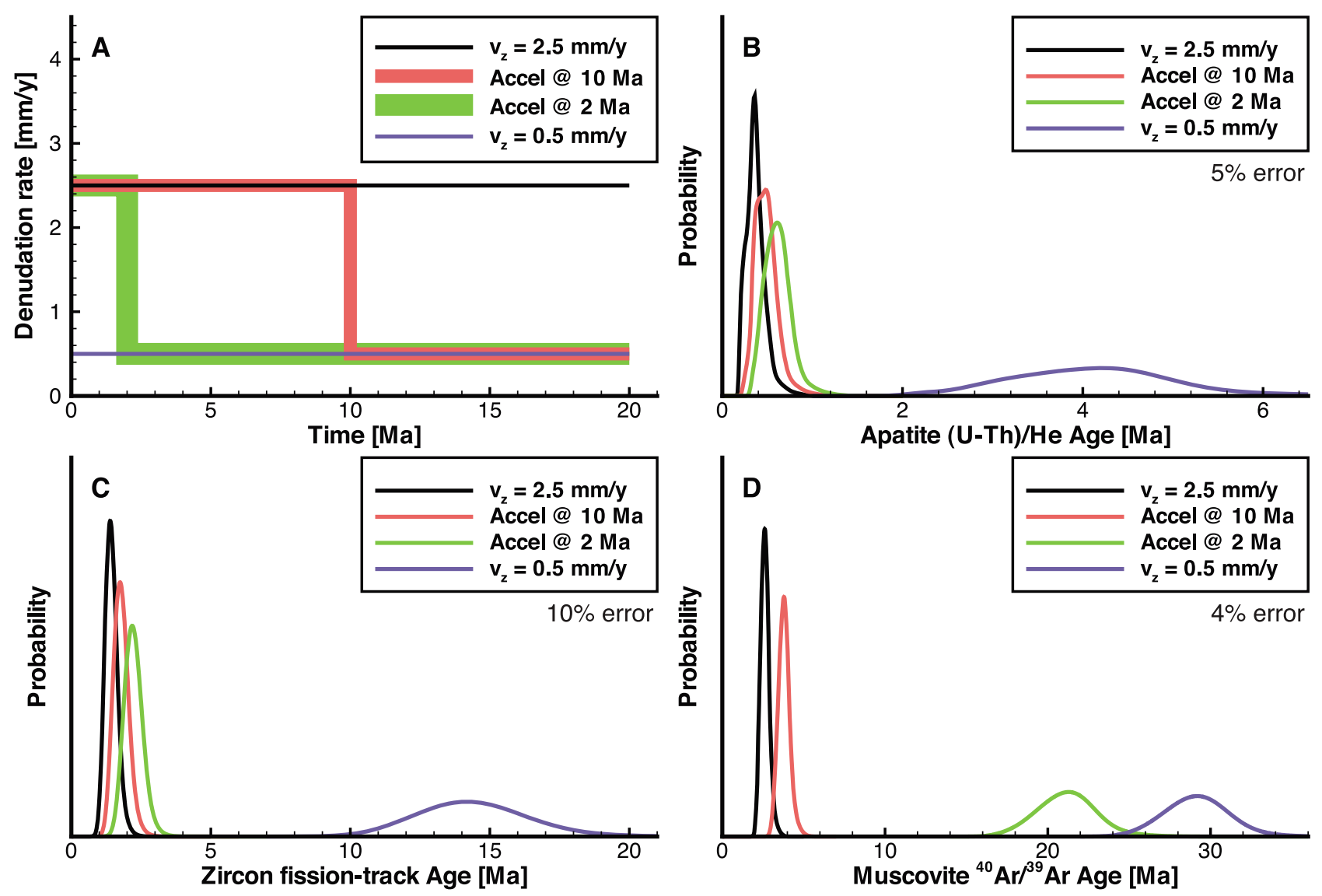

Figure 5. Effect of temporal variations in denudation rate on predicted age distributions. (a) Timeinvariant denudation rates of 2.5 (black) and $0.5 \mathrm{~mm} / \mathrm{y}$ (blue) are shown with rates that increase from 0.5 to $2.5 \mathrm{~mm} / \mathrm{y}$ at either $10 \mathrm{Ma}$ (red) or $2 \mathrm{Ma}$ (green). These models use the vertical kinematic scenario to predict (b) AHe, (c) ZFT, and (d) MAr age distributions. The listed percent error is the $1 \sigma$ uncertainty used in generating the predicted $\mathrm{SPDF}_{m}$ curves.

For the vertical and lateral kinematic models used here, the denudation rate is $1 \mathrm{~mm} / \mathrm{y}$. For the thrust model, most of the basin investigated has a denudation rate of $1 \mathrm{~mm} / \mathrm{y}$, and a small section has a denudation rate of $0.27 \mathrm{~mm} / \mathrm{y}$ due to the ramp flat geometry of the underlying thrust fault (Figure 7a). The denudation rates are constant with time, with the exception of the thrust model as explained below, and the surface topography does not change.

[30] The peak ages and age ranges of the vertical and lateral kinematic scenarios are quite similar, with a general trend of younger peak ages and a slight increase in the age ranges in the lateral scenario. As mentioned above, both scenarios have denudation rates of $1 \mathrm{~mm} / \mathrm{y}$, but in order to generate the $1 \mathrm{~mm} / \mathrm{y}$ denudation rate with the lateral model, the magnitude of the advection velocity vectors parallel to the prescribed $40^{\circ}$ dip must be larger than those in the vertical model. The net effect of the lateral model velocity vectors is advection of heat from the northern margin of the model into the center of the model domain (Figure 3), slightly warming the region beneath the basin of interest. The temperature increase in that area generates the slightly younger peak ages, while the lateral velocity component produces a slight increase in age range. In the AHe system, this can be seen by a peak age that is $\sim 1.1$ times younger for the lateral kinematic model. For the same kinematics, the age range increases slightly (Figure $7 \mathrm{~b}$ ). This age trend is also present in the higher temperature thermochronometer systems. For the ZFT system, the peak age is $\sim 1.2$ times younger with almost no increase in the age range for the lateral model (Figure 7c). Similarly, the peak age for the MAr system is $\sim 1.1$ times younger and the age range shows a slight increase (Figure 7d).

[31] The thrust scenario exhibits notably different age distributions than the vertical and lateral kinematic scenarios. First, although the majority of the basin area has a surface denudation rate of $1 \mathrm{~mm} / \mathrm{y}$ by the end of the model run at $0 \mathrm{Ma}$, lateral advection of the faults generates temporal changes in the denudation rate (Figure $7 \mathrm{a}$ ). For the majority of the basin, the background denudation rate for the early portion of the model run is $0.27 \mathrm{~mm} / \mathrm{y}$ as the hanging wall of the model thrust sheet is moving over a fault with a $10^{\circ}$ dip angle. As material moves into the more steeply dipping section, the denudation rate increases to $1 \mathrm{~mm} / \mathrm{y}$. Second, underthrusting of material leads to an overall cooling of the near surface and a general trend of older ages. With these two points in mind, consider the AHe thermochronometer system. As Figure $7 \mathrm{~b}$ shows, the peak age from the thrust model is $\sim 1.8$ times older than the vertical model peak. In this case, the age difference reflects earlier cooling below the effective AHe closure isotherm in the 

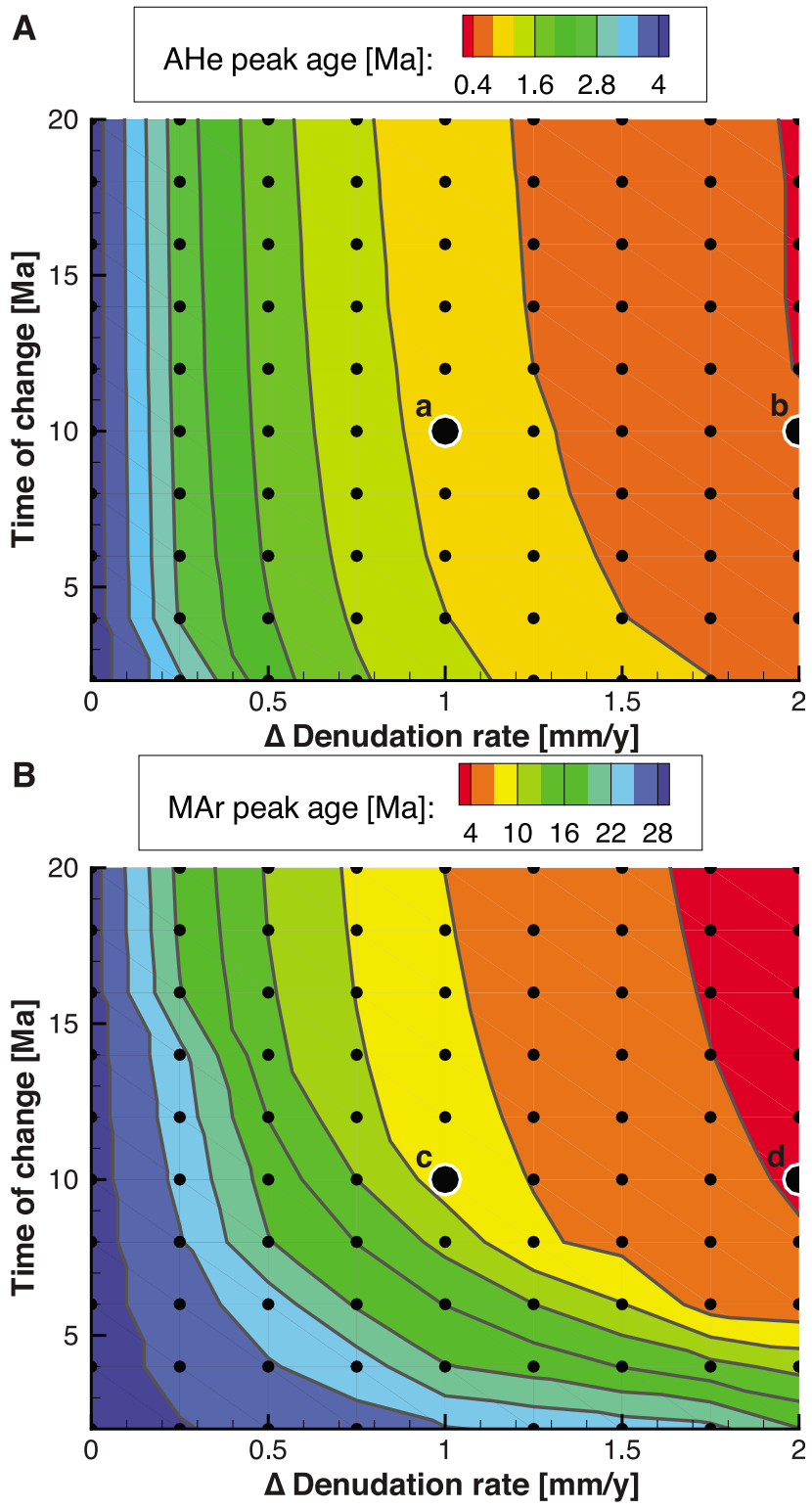

Figure 6. Changes in peak ages resulting from an acceleration in denudation rate at various times. The background denudation rate of $0.5 \mathrm{~mm} / \mathrm{y}$ is accelerated by $0-2 \mathrm{~mm} / \mathrm{y}$ at 2-20 Ma. Each small black circle represents an individual model run from which the contoured (a) $\mathrm{AHe}$ and (b) MAr peak ages were derived. The larger black circles are discussed in the text.

cooler thermal field. In addition, the age distribution has a long tail, resulting in an age range for the thrust model that is significantly larger than the range for either the vertical or lateral models. This range reflects the fact that a small portion of the drainage basin has a slower background denudation rate and that the rate has varied spatially with time. The ZFT thermochronometer has a similar trend to the AHe system, with an older peak age and much larger age range. In this case, the peak age is $\sim 1.6$ times older than the vertical model peak age and the age range is $\sim 12$ times larger. The increase in offset of the peak ages reflects the fact that a larger portion of the ZFT cooling history occurs with the slower denudation rate and the large age range is the result of unreset ZFT ages due to insufficient exhumation. Last, the MAr system peak age is $\sim 1.6$ times older than the age from the vertical kinematic model, while the age range is $\sim 9$ times larger.

\subsection{Effects of Evolving Topography}

[32] In contrast to the sections above that explored how variations in exhumation rate and pathway affect cooling ages, this section looks at how detrital age distributions change in response to evolution of surface topography. To illustrate this effect, we highlight two models that feature a $50 \%$ increase in topographic relief across the model region. Relief increases from $50 \%$ to $100 \%$ of the observed modern relief about either a fixed minimum or fixed maximum elevation, simulating relief development from maintaining a constant base level or incising a valley with a constant peak elevation, respectively (Figure 8a). The changes in topography occur linearly through time over the last $10 \mathrm{My}$ of the model run. Although we do not present results of a $50 \%$ decrease in relief, we note that it has a similar magnitude effect to a $50 \%$ increase, with the opposite trend. In addition to evolving surface topography, models in this section use the vertical kinematic scenario with a constant prescribed denudation rate of $1 \mathrm{~mm} / \mathrm{y}$. Thus, the combination of the background denudation rate and topographic change yields an effective denudation rate range of $0.61-0.96 \mathrm{~mm} / \mathrm{y}$ for increasing relief about a fixed minimum elevation. When the maximum elevation is fixed, the effective denudation rate range increases to $1.04-1.39 \mathrm{~mm} / \mathrm{y}$. Denudation rate changes at the catchment outlet occur because that point is $\sim 800 \mathrm{~m}$ above the minimum elevation in the model domain, whereas the highest elevation in the catchment is $<200 \mathrm{~m}$ below the highest model surface elevation. Results are compared to a simulation with steady state modern relief and a background denudation rate of $1.0 \mathrm{~mm} / \mathrm{y}$.

[33] The primary effect of the topographic relief change scenarios is younger peak ages for scenarios that generate higher effective denudation rates and older peak ages for those that generate lower denudation rates. For example, in the fixed minimum elevation scenario, the AHe peak age is $\sim 1.3$ times older than the no relief change model, whereas the peak age from the fixed maximum scenario is $\sim 1.2$ times younger (Figure 8b). Again, as was the case in the previous sections, the ZFT and MAr systems behave in a similar manner; in the constant minimum elevation models the peak ages are $\sim 1.2$ times older relative to the fixed relief model for both thermochronometers, while the age peaks in both systems are $\sim 1.2$ times younger for the fixed peak simulations (Figures $8 \mathrm{c}$ and $8 \mathrm{~d}$ ). One trend shown by the changes in peak age is that low-temperature thermochronometers (e.g., $\mathrm{AHe}$ ) have a slightly larger sensitivity to relief changes. This is perhaps not unexpected as the effective closure temperature isotherm for the AHe system resides much closer to the surface. Furthermore, lower temperature thermochronometers are expected to have greater sensitivity to changes in relief for short $(\sim 10 \mathrm{~km})$ wavelength topographies [e.g., Braun, 2002]. As before, increased denudation rates also generate narrower age ranges.

\subsection{Effects of Basin Size}

[34] The final factor expected to affect detrital age distributions is the size of the basin used to extract cooling ages from the model. As opposed to the previous sections 
A

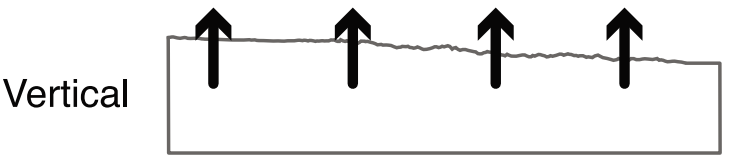
Lateral

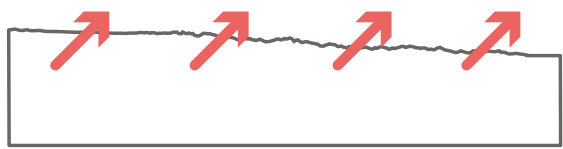

Thrust
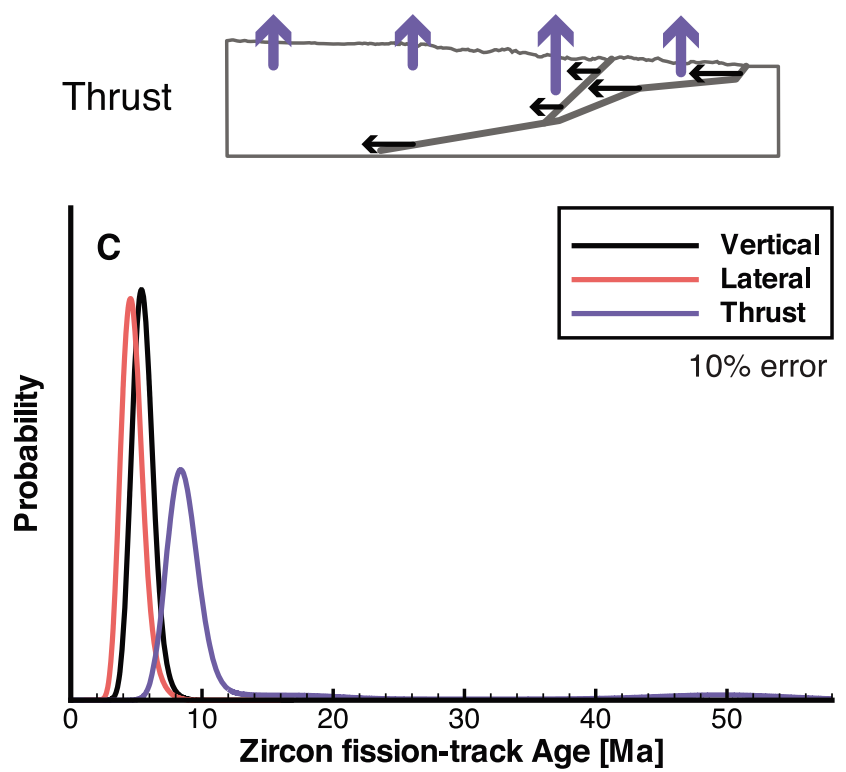
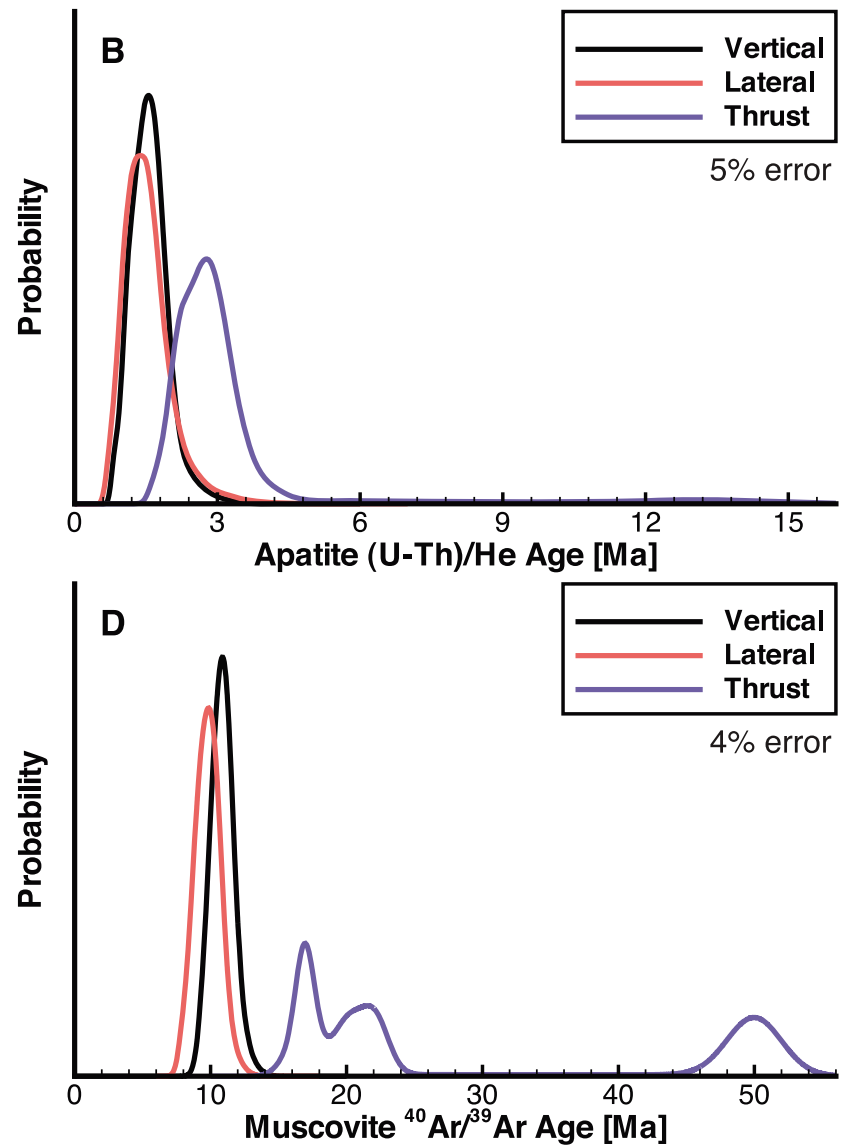

Figure 7. Effect of different kinematic scenarios on predicted age distributions. (a) Schematic cross sections showing velocity vectors in the vertical (black), lateral (red), and thrust (blue) kinematic scenarios. These models generally have a denudation rate of $1 \mathrm{~mm} / \mathrm{y}$ (see text for details) and are used predict (b) AHe, (c) ZFT, and (d) MAr age distributions. The listed percent error is the $1 \sigma$ uncertainty used in generating the predicted $\mathrm{SPDF}_{m}$ curves.

that looked at how various model inputs affected the predicted cooling age distribution, the only free parameter in this section is the area from which cooling ages are extracted. In addition to the catchment that has been used for the previous sections, we examine age distributions from two tributary catchments of varying size (Figure 9a). The largest catchment and focus thus far has a drainage area of $\sim 2775 \mathrm{~km}^{2}$ with $7164 \mathrm{~m}$ of relief. The intermediate catchment is only $\sim 59 \%$ of the size of the large catchment with $5315 \mathrm{~m}$ of relief. The smallest catchment has a drainage area that is $\sim 30 \%$ of the large catchment and $4097 \mathrm{~m}$ of topographic relief. For the comparison of age distributions in this section, models use the vertical kinematic scenario with a background denudation rate of $1 \mathrm{~mm} / \mathrm{y}$ and have no change in the surface topography.

[35] Results indicate that the peak ages generated from the three catchments of differing basin area and relief do not vary appreciably (Figures 9b-9d). The AHe peak age for the largest basin is $1.6 \mathrm{Ma}$ and the peak ages for the medium and small catchments both only increase by $<2 \%$. The trend is the same for the ZFT and MAr age distributions with ages increasing by only $1-2 \%$ for both the medium and small catchments. The age ranges are affected slightly more by the catchment size with the predicted $\mathrm{AHe}$ age distribution from the small catchment showing the maximum effect with an age range that is $\sim 1.4$ times smaller.

\section{Discussion}

[36] We now turn our focus to specific applications of detrital thermochronometers and the implications of the previous results on them. We start by addressing the question of when the interpretation of detrital thermochronometer data is affected by 1-D techniques and when a 3-D model could improve on those results. We then extend our results to discuss temporal trends that might be observed in detrital thermochronometer data collected in sedimentary basins. We conclude with a discussion of the issue of nonuniqueness in detrital thermochronology and what numerical models can provide in terms of reducing interpretation uncertainties.

\subsection{When Is a 3-D Thermal Model Necessary?}

[37] A common application of detrital thermochronometer data from modern river sediments is the estimation of basin-wide denudation rates. The generation of detrital thermochronometer data sets takes a substantial effort, and the determination of denudation rates from these data 
A
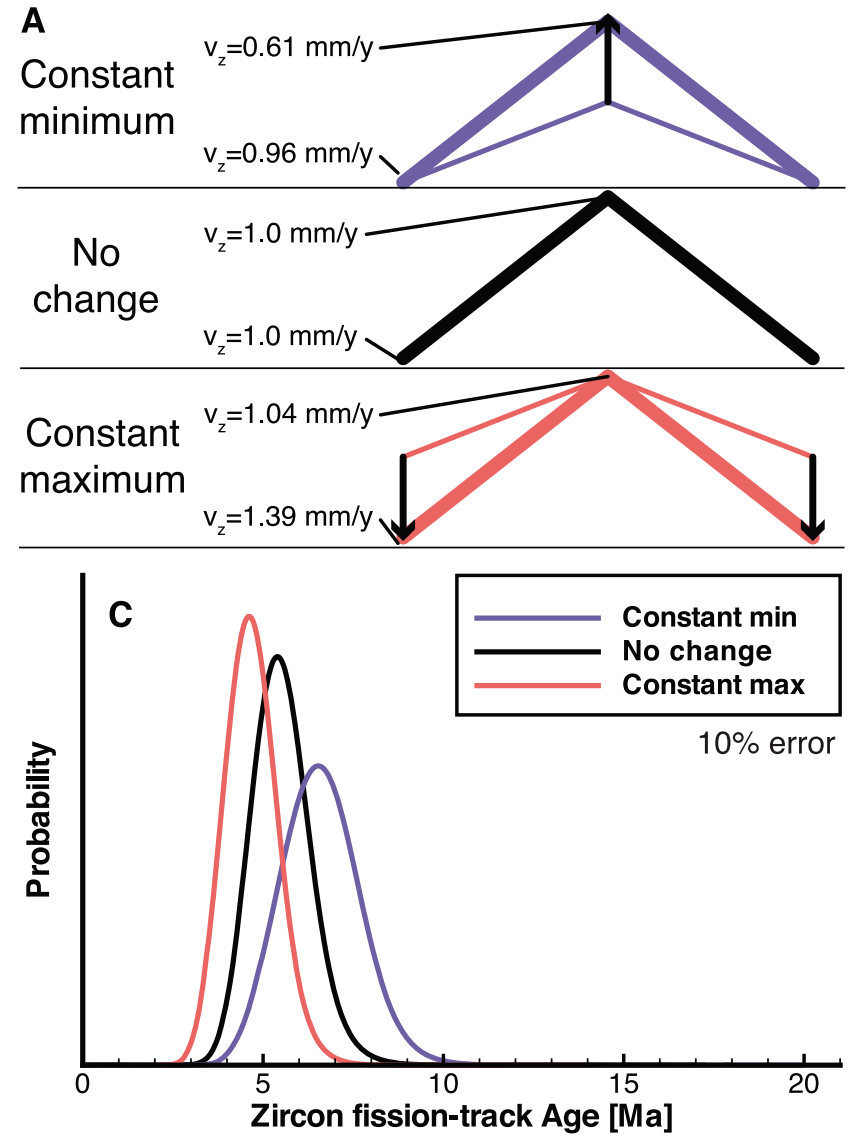
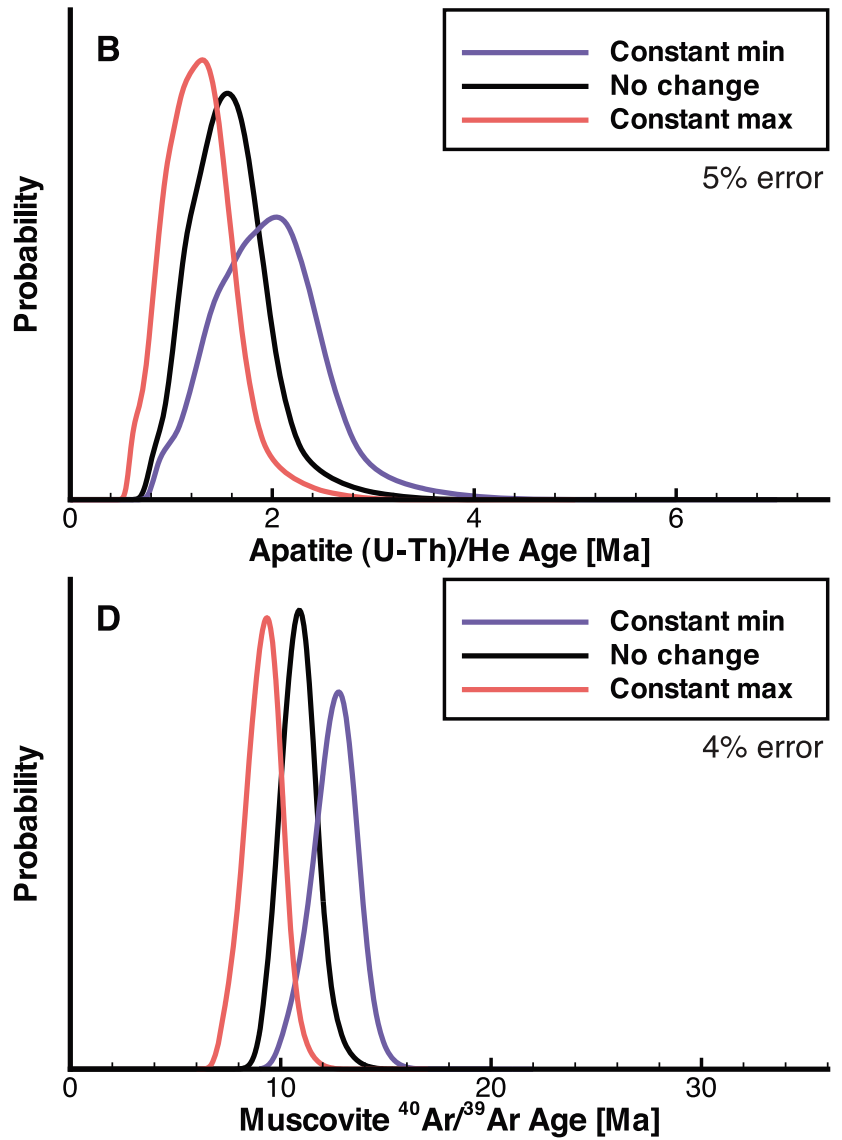

Figure 8. Effect of increasing topographic relief on predicted age distributions. (a) Schematic cross sections of time-invariant surface topography (black) and a 50\% increase in relief about either a fixed minimum (blue) or a fixed maximum (red) elevation. These models are used to predict (b) AHe, (c) ZFT, and (d) MAr age distributions. The listed percent error is the $1 \sigma$ uncertainty used in generating the predicted $\mathrm{SPDF}_{m}$ curves.

requires careful consideration of the factors that can potentially influence the calculation. One basic method for the calculation of basin-wide denudation rates involves simply dividing the catchment elevation range by the range of cooling ages [e.g., Brewer et al., 2003; Ruhl and Hodges, 2005]. In essence, this interpretation is the same as using a linear relationship between sample age and elevation (e.g., Figures 1a-1d). Because that is the case, the true denudation rate will only be recovered if the effective closure isotherm of interest resides at a constant depth and is not significantly perturbed by the surface topography, groundwater circulation, faulting, variability in thermophysical rock properties, or other similar influences [e.g., Whipp and Ehlers, 2007; Whipp et al., 2007]. If the isotherm is perturbed by the overlying topography, as is commonly the case in high-relief mountain ranges, then estimates of the denudation rate based on the methodology above will tend to overestimate the true denudation rate, provided that rock transport to the surface does not have a large lateral velocity component. In this case, the data interpretation may be improved through the use of 3-D numerical models that can account for many of the dominant influences on the crustal thermal field. However, 3-D numerical models are complex and their predictive capability is limited by the constraints on the model free parameters. In cases where few constraints exist, a 3-D numerical model may provide no better denudation rate estimate than a simple calculation assuming a linear ageelevation relationship. For the purposes of this section, we analyze how 1-D and 3-D methods differ in their predicted denudation rates assuming that the model parameters for the 3-D model are well constrained.

[38] Comparison of the prescribed model denudation rate to that predicted using the catchment elevation range divided by the model-predicted age range shows consistent overestimation, particularly for low-temperature thermochronometers and high denudation rates. The comparison is performed on the models discussed in Section 3.1.1, where the vertical kinematic scenario was used with time invariant denudation rates and topography. For the $\mathrm{AHe}$ system, even at the relatively slow prescribed denudation rate of $0.5 \mathrm{~mm} / \mathrm{y}$, the rate estimate using the 1-D method of Ruhl and Hodges [2005] is $1.4 \mathrm{~mm} / \mathrm{y}, 2.8$ times higher than the 3-D model-prescribed rate. As the prescribed rate increases, the overestimate also climbs, with a calculated rate that is 4.8 times greater than the prescribed rate of $2.5 \mathrm{~mm} / \mathrm{y}$. For higher-temperature thermochronometers, such as MAr, there is significant improvement to the overestimation, with the overestimate decreasing to be only 1.4 times higher than the 3-D model-prescribed rate at a rate of $0.5 \mathrm{~mm} / \mathrm{y}$. However, at a rate of $2.5 \mathrm{~mm} / \mathrm{y}$, the 
A
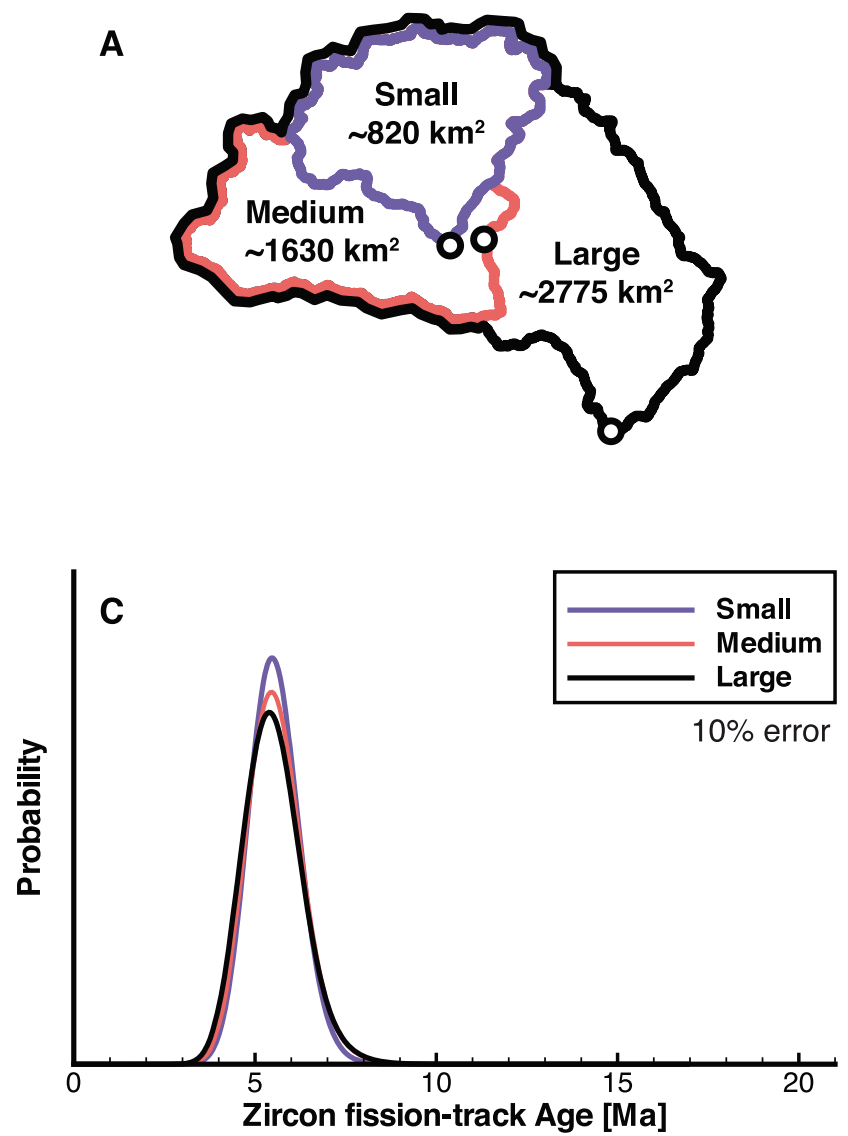
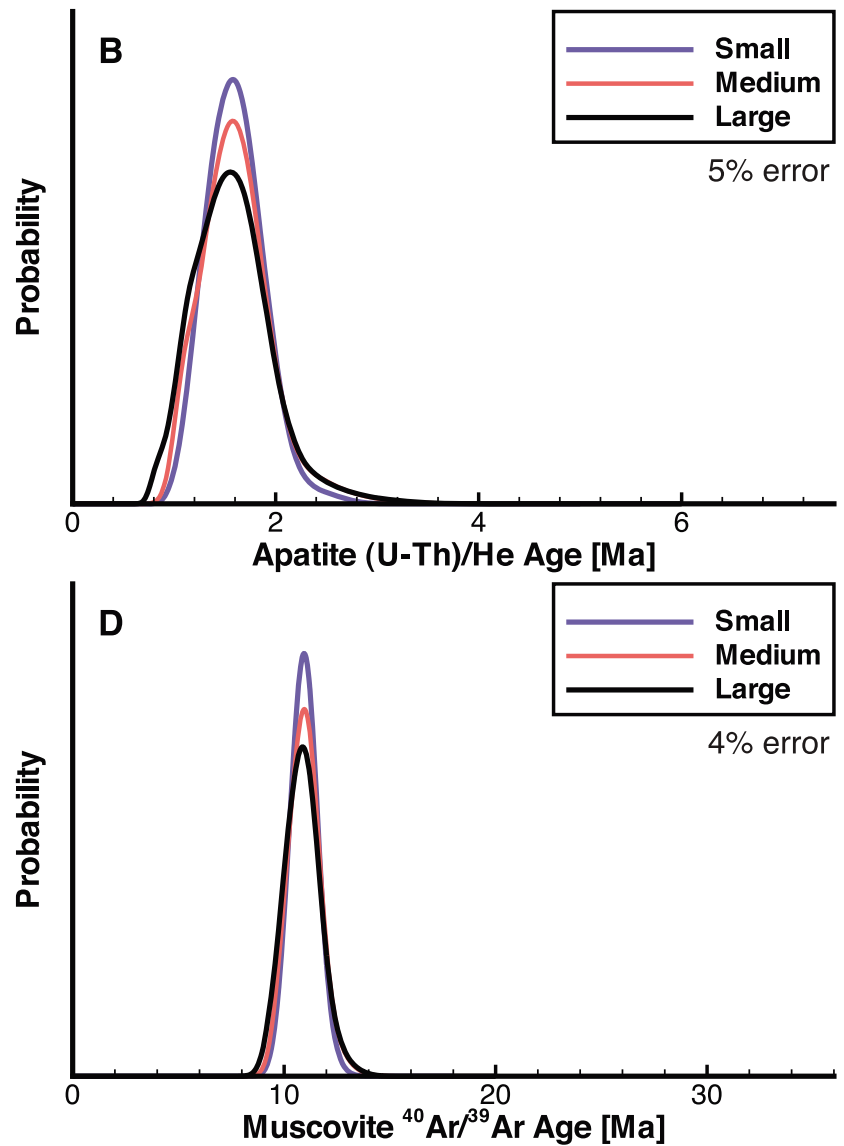

Figure 9. Effect of basin size on predicted age distributions. (a) Different basin sizes used for age prediction where the large basin (black) is the basin used in all previous age distributions and the medium (red) and small (blue) basins are tributary catchments to the large basin. For each basin, (b) AHe, (c) ZFT, and (d) MAr age distributions are predicted. The listed percent error is the $1 \sigma$ uncertainty used in generating the predicted $\mathrm{SPDF}_{m}$ curves.

overestimate again increases to be $\sim 2$ times the prescribed value. It is important to note, though, that prescribing vertical velocities across the entire lithosphere $(130 \mathrm{~km})$ in our simulations enhances the thermal effect of surface denudation. This enhancement is predicted by the Peclet number for the model $\left(\mathbf{P e}=v_{z} L / \kappa\right.$, where $\mathrm{v}_{z}$ is the denudation rate, $L$ is the thickness of the model lithosphere, and $\kappa$ is the thermal diffusivity). Even at a relatively slow denudation rate of $0.5 \mathrm{~mm} / \mathrm{y}$, the Peclet number for the model geometry is $\approx 2$. In mountain ranges where vertical motion of material applies to a thinner region, such as only the crust, the Peclet number would be smaller and decrease magnitude of the effect of mass advection, resulting in a smaller rate difference between 1-D and 3-D techniques. Further comparison using additional rates and thermochronometer systems can be found in Table 2 .

[39] Overall, the comparison between 1-D and 3-D techniques shows potential for significant overestimation of denudation rates using 1-D methods and that 3-D models may provide better rate estimates when their parameters are well constrained. For a 1-D interpretation, the potential for overestimation can be minimized by using higher-temperature thermochronometers or by applying the technique in regions thought to be eroding at slower rates. The overestimation of denudation rates may also decrease through the use of other thermal modeling techniques. For example, the 2-D approach of Brewer et al. [2003] used a prescribed denudation rate to predict an age-elevation relationship that was convolved with the basin hypsometry to generate a predicted PDF. Assuming insignificant lateral variations in the subsurface thermal field in the region of interest such that the 2-D model can be extrapolated to three dimensional and good constraints on the model parameters, the input denudation rate should provide a good estimate of the true denudation rate when the modelpredicted and observed age PDFs are similar. Caution should still be used, though, with low-temperature thermochronometers as those systems will be more sensitive to the 3-D variability in the surface topography. Transient 1-D thermal models, such as that utilized by Rahl et al. [2007], where cooling ages are calculated from a predicted 1-D cooling history, may also be used for estimating denudation rates, but the applications are more limited. Models of that type could be used to estimate basin-wide denudation rates by varying the model-prescribed denudation rate until a good fit is observed between the predicted cooling age and the peak age of a given catchment age distribution. However, 1-D thermal models should be used with care as they do not generate an age-elevation relationship or utilize the basin hypsometry. For instance, the use of 1-D thermal models to interpret detrital data from both a small tributary high up in a 
Table 2. Comparison to Denudation Rates Predicted Using Method of Ruhl and Hodges [2005]

\begin{tabular}{lcccc}
\hline System & $\begin{array}{c}\text { Input Rate } \\
(\mathrm{mm} / \mathrm{y})\end{array}$ & $\begin{array}{c}\text { Age Range } \\
(\mathrm{Ma})\end{array}$ & $\begin{array}{c}\text { Estimated Rate } \\
(\mathrm{mm} / \mathrm{y})\end{array}$ & $\begin{array}{c}\text { Overestimate } \\
(\%)\end{array}$ \\
\hline $\mathrm{AHe}$ & 0.5 & 5.3 & 1.4 & 180 \\
$\mathrm{AHe}$ & 1.0 & 2.2 & 3.3 & 230 \\
$\mathrm{AHe}$ & 2.5 & 0.6 & 12.0 & 380 \\
$\mathrm{ZFT}$ & 0.5 & 10.5 & 0.7 & 40 \\
$\mathrm{ZFT}$ & 1.0 & 4.3 & 1.7 & 70 \\
$\mathrm{ZFT}$ & 2.5 & 1.2 & 6.0 & 140 \\
$\mathrm{MAr}$ & 0.5 & 10.5 & 0.7 & 40 \\
$\mathrm{MAr}$ & 1.0 & 4.6 & 1.6 & 60 \\
$\mathrm{MAr}$ & 2.5 & 1.4 & 5.1 & 104 \\
\hline
\end{tabular}

${ }^{\mathrm{a}}$ Calculated using catchment relief of $7.164 \mathrm{~km}$.

large catchment and the trunk stream may yield differences in the best fit predicted denudation rate. In reality, the entire catchment may be eroding at the same rate, but because the 1-D thermal model does not account for topography, predicted rate differences could arise. Thus, 1-D thermal models should only be used in areas with relatively simple basin hypsometries, unimodal elevation distributions and an elevation frequency peak that falls near the middle of the elevation range. Detrital thermochronometer data from regions with highly skewed or multimodal hypsometries are better interpreted using 2-D or 3-D models, provided data are available to place limits on the model parameter ranges.

\subsection{Transient Record in Basin Stratigraphy}

[40] One of the emerging and potentially most powerful applications of detrital thermochronology is the use of temporal records of denudation preserved in foreland basin sediment sequences to quantify the magnitude and timing of exhumation driven by hinterland tectonic or climatic variability [e.g., Cerveny et al., 1988; Copeland and Harrison, 1990; Renne et al., 1990; Brandon and Vance, 1992; Garver and Brandon, 1994a; Bernet et al., 2006; Carrapa et al., 2006; Coutand et al., 2006; Kuhlemann et al., 2006; Sobel et al., 2006; Szulc et al., 2006; van der Beek et al., 2006]. One common tool for interpreting these transient data sets is to identify changes in lag time [e.g., Bernet and Garver, 2005, and references therein]. Lag time changes are often interpreted to reflect changes in hinterland denudation rate, but may also result from topographic evolution. To quantify the magnitude of these effects, we present below two models that explore how changes in denudation rate and topography affect a 15 My record preserved in foreland basin sediments. The first model contains the record of a fivefold increase in denudation rate at $10 \mathrm{Ma}$ with fixed topography. The second model features a uniform background exhumation rate of $1 \mathrm{~mm} / \mathrm{y}$ and simulates a $50 \%$ increase in topographic relief from 10 to $0 \mathrm{Ma}$. Both models use the vertical kinematic scenario and are compared to models that do not change the parameter of interest with time. The examples presented here are based on the models described in Sections 3.1.2 and 3.3. For this analysis, we assume that the basin boundary does not change with time and sample burial depth is sufficiently small such that cooling ages will not be reset after deposition.

[41] The foreland basin record of a fivefold increase in denudation rate shows an initial shift in peak age, followed by a narrowing of the catchment age range. As shown in
Figure $10 \mathrm{a}$, there is no difference between the age distributions of the model with a fixed denudation rate of $0.5 \mathrm{~mm} / \mathrm{y}$ and the acceleration model prior to $10 \mathrm{Ma}$. Both models show peak ages of $\sim 44 \mathrm{Ma}$ and age ranges of $\sim 13 \mathrm{Ma}$, with the age range reflecting the $4 \% 1 \sigma$ error used in generating the model $\mathrm{SPDF}_{m}$. By $5 \mathrm{Ma}$, with $5 \mathrm{My}$ of denudation at the higher rate of $2.5 \mathrm{~mm} / \mathrm{y}$, the age distribution for the acceleration model begins to diverge from the constant $0.5 \mathrm{~mm} / \mathrm{y}$ model. The peak age of the acceleration model decreases to $\sim 15$ Ma relative to the $\sim 34$ Ma peak age of the slow denudation rate model with little change in the age range. This shift to a younger peak age without a significant change in age range reflects the onset of the more rapid denudation rate without exhumation of samples that cooled below their effective closure temperature at the more rapid rate. By $0 \mathrm{Ma}$, the peak age of the acceleration model has decreased to $\sim 5 \mathrm{Ma}$, only $\sim 2$ My older than the peak age of the constant fast $(2.5 \mathrm{~mm} / \mathrm{y})$ denudation rate model. In this case, the age range is also $\sim 5$ times smaller and quite similar to the age range of the high denudation rate model. Thus, the overall trend for a fivefold acceleration in denudation rate is an initial decrease in peak age with little change in age range, followed by decreases in both the peak age and age range.

[42] A less pronounced detrital grain age signal is visible in basin sediments where the upstream area has experienced relief change. Increasing relief by $50 \%$ beginning at $10 \mathrm{Ma}$ shows very little change in the resulting age distributions. As Figure 10b shows, the age distributions prior to any topographic change at 15 and $10 \mathrm{Ma}$ are almost identical, with no differences in the peak ages and an age range that is $\sim 1.2$ times smaller in the topographic evolution model, in spite of one model having topography with $50 \%$ of the modern relief and the other $100 \%$ of the modern relief. By $5 \mathrm{Ma}$, as the relief begins to increase in the changing relief model, the age range increases to only $\sim 1.1$ times smaller than the fixed topography model, but the peak ages remain almost identical. By $0 \mathrm{Ma}$, however, both the peak age and age range show a more significant difference relative to the fixed topography model, with values that are $\sim 1.1$ and $\sim 1.2$ times higher, respectively. In this case, the older peak age and larger age range are the result of slower denudation rates resulting from the increase in basin elevations with a constant background denudation rate. All told, however, the observed differences in the peak age and age range of the changing relief model relative to the fixed topography model are likely not detectable in real data. The age distributions in Figure 10b are too similar at each sampled time and would not yield statistically different age distributions using common statistical tests such as the two-sample Kolmogorov-Smirnov or Kuiper's tests [e.g., Press et al., 1992; Amidon et al., 2005; Ruhl and Hodges, 2005, and references therein] without dating an unusually high number of sample grains $(\gg 100)$. It is worth noting, however, that topographic evolution scenarios in areas with longer wavelength topography [e.g., Braun, 2002], more rapid changes in relief or slower background denudation rates may increase the difference in age distributions.

[43] In addition to changes in the age distributions, changes in hinterland erosion from detrital thermochronometers are often expressed in changes in lag time. As defined by Garver and Brandon [1994b], the lag time is the 


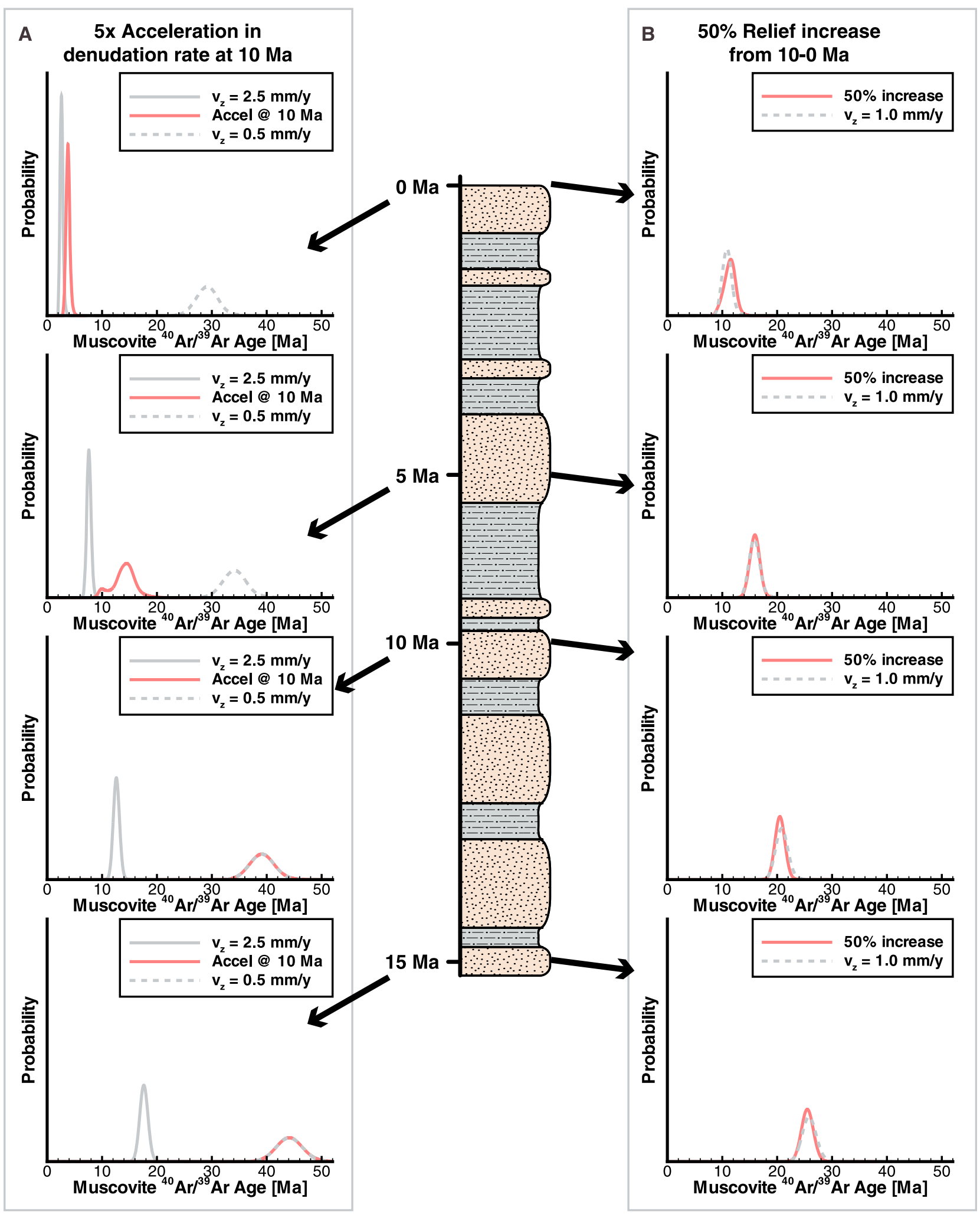

Figure 10. Temporal response to changes in denudation rate and topographic relief at 10 Ma that may be recorded in foreland basin sediments. Schematic stratigraphic column represents sediment preserved from 15 to $0 \mathrm{Ma}$ and sampled at $5 \mathrm{My}$ intervals. (a) Predicted MAr age distributions for a $5 \times$ acceleration in denudation rate (red) shown with distributions generated with time-invariant denudation rates of 2.5 (solid gray) and $0.5 \mathrm{~mm} / \mathrm{y}$ (dashed gray) using the vertical kinematic scenario. (b) Predicted MAr age distributions for a 50\% increase in topographic relief (red) and that predicted for time-invariant topography (dashed gray). Both models use the vertical kinematic scenario with a background denudation rate of $1 \mathrm{~mm} / \mathrm{y}$. All vertical axes are at the same scale. 


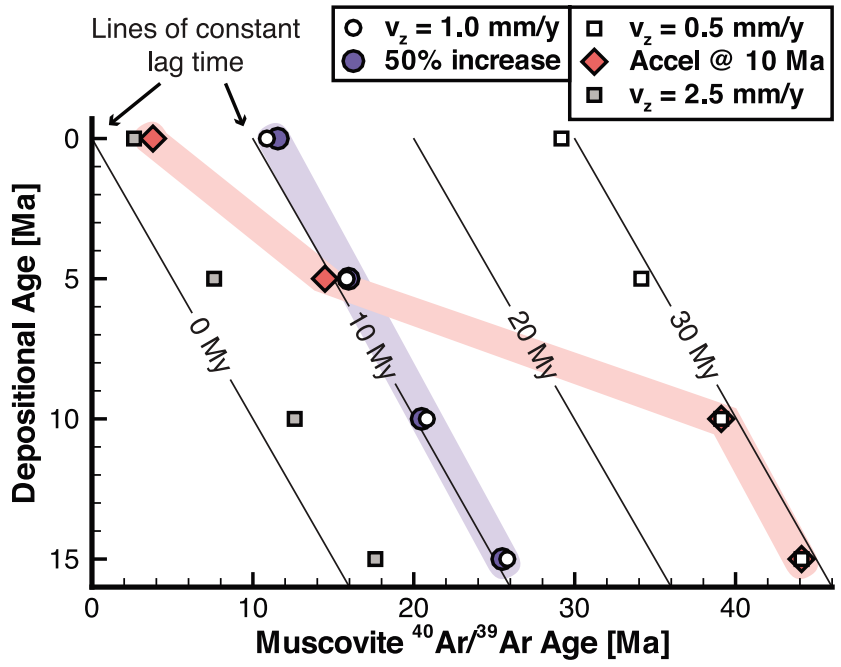

Figure 11. Changes in lag time for variations in denudation rate and topographic relief predicted in foreland basin deposits. Peak ages are plotted for the denudation rate and topographic change scenarios shown in Figure 10 (within colored zones). Symbols that are plotted along the lag time contours (thin black lines) show no change in lag time in the hypothetical deposits.

age difference between the measured thermochronometer age and the depositional age of the sampled sedimentary unit. Thus, the lag time is a measure of the time required for the thermochronometer sample ages that form the peak age to travel from the depth of their effective closure temperature isotherm to the surface and then to their depositional basin. In general, for active orogens, the transport time at the surface is considered negligible. For example, in the denudation rate change model in Figure 10a, the lag time rapidly decreases from $\sim 29 \mathrm{My}$ at $10 \mathrm{Ma}$ to $\sim 4 \mathrm{My}$ at $0 \mathrm{Ma}$. In contrast, the lag time for the constant 0.5 and $2.5 \mathrm{~mm} / \mathrm{y}$ denudation rate models are $\sim 29$ and $\sim 2.6$ My at all times (15-0 Ma). These trends are easily seen in plots of cooling age versus depositional age (e.g., Figure 11), where lines of constant lag time help accentuate changes in denudation rate. In this case, the constant denudation rate models plot along lines of constant lag time (squares in Figure 11), while the acceleration model crosses the lag time contours (diamonds in Figure 11). In contrast, for the topographic evolution model, age peaks with and without evolving topography plot along a lag time contour line (circles in Figure 11). This is not unexpected as the denudation rate variations in the relief change model are small $(<0.4 \mathrm{~mm} / \mathrm{y})$.

\subsection{Nonuniqueness}

[44] One of the potential problems with the interpretation of both bedrock and detrital thermochronometer data is nonuniqueness. This issue has been discussed by a number of authors (e.g., van der Beek et al. [1999], Gunnell [2000], Ehlers [2005], Reiners et al. [2005], Bollinger et al. [2006], Rahl et al. [2007], Whipp et al. [2007], and many others) and arises from uncertainty in the large number of factors that can affect the cooling history of a given thermochronometer sample. For instance, the thermal effects of a slightly higher denudation rate might be similar to that of higher volumetric heat production. All other things equal, pre- dicted thermochronometer ages from either of those model variants might be statistically equal. If nothing else is known about the material properties or denudation history of a given region from other data and the model predictions fit a data set equally well, then one must conclude that either of the model options is plausible. Clearly, this highlights the need to constrain as many model free parameters as possible using material thermal property measurements and other proxy data. In addition, unknown model parameters should be assigned a range of values that encompasses the potential parameter space in order to ensure that conclusions from the applied model are robust.

[45] There are some model parameters, however, that will tend to have a larger impact on the thermal field and predicted thermochronometer ages than others. In our detrital modeling study, is it clear that the denudation rate has a large impact on the predicted thermochronometer age distributions (Figure 4). The timing of denudation rate changes can also significantly affect the age distributions, but the timing of a rate change may be difficult to constrain depending on the thermochronometer system (Figures 5b, $5 \mathrm{~d}$, and 6 ). The exhumation kinematics may also have a strong effect on age distributions, but similar to the conclusions of Whipp et al. [2007], it appears that the denudation rate dominates the effect of kinematics with low-temperature thermochronometers (Figure 7b). Both topographic change and basin size had smaller impacts on the predicted age distributions in the model parameter space we explored. This suggests that relief change would likely be difficult to detect and that basin size is not as important as the location of the basin with respect to spatial variations in denudation. Thus, in rapidly eroding, active orogens we expect the denudation rate to be the most dominant factor affecting thermochronometer age distributions with the kinematics being of significant concern with higher temperature systems. This implies that although uncertainty in other model parameters may exist, significant conclusions can be drawn using low-temperature thermochronometer data sets and more simple numerical models that only consider the effects of variable denudation rate and timing of rate changes. It should be noted, however, that this may not be the case in more slowly eroding orogens, and interpreting data from regions with large magnitude, recent topographic changes may require the use of more sophisticated models.

\section{Conclusions}

[46] In this study we used a 3-D thermokinematic and erosion numerical model to explore the response of detrital thermochronometer age distributions to changes in denudation rate, exhumation kinematics, topographic evolution and basin size. The major conclusions of this work are as follows.

[47] 1. Detrital denudation rate estimates made using 1-D assumptions about the thermal field show potential for a significant overestimate compared to 3-D thermal models, particularly for low-temperature thermochronometers. At a background denudation rate of $2.5 \mathrm{~mm} / \mathrm{y}$, the AHe predicted denudation rate using a 1-D technique is 4.8 times greater than the 3-D model prescribed. With the MAr thermochronometer, that same rate reduced the overestimate to be only 2 times the model rate. Although these rates may be quite 
high, they are typical of active orogens (such as the Himalaya, Southern Alps and Taiwan). In more slowly eroding regions, use of 1-D techniques may be of greater benefit. It is also important to note, however, that 3-D model-derived rate constraints are only as good as the available data that define the model parameter range. Thus, we urge general caution in calculating denudation rates in active orogens.

[48] 2. Low-temperature thermochronometers may be of greater utility than higher temperature systems in trying to interpret recent $(\leq 2 \mathrm{Ma})$ changes in denudation rate. However, as the response time of the low-temperature systems is shorter, higher temperature systems may be of greater use for rate change detection further in the past $(\sim 5-20 \mathrm{Ma})$.

[49] 3. An acceleration in denudation rate that could potentially be observed in foreland basin sediments is characterized by an initial decrease in peak age with a fairly constant age range, followed by a further decrease in peak age and age range. The overall rate change can easily be observed by calculating the changes in lag time, however a substantial time may pass before the age range in a given sample decreases following the rate change.

[50] 4. Variations in the background denudation rate dominate the influence of other explored parameters with low-temperature thermochronometers. The observed peak age shifts and age range changes resulting from changing denudation rates would be expected to mask the effects of other potential forcings.

[51] 5. The exhumation kinematics can also have a strong influence on the predicted age distributions, particularly with higher temperature thermochronometer systems. Although no significant difference in age distributions for the lateral versus vertical kinematic scenarios is observed, the thrust faulting model showed substantial difference in the cooling ages. As suggested by Whipp et al. [2007], thermochronometer studies that seek to constrain the faulting history of rapidly eroding, active orogens would be best served using systems such as MAr, which will integrate their cooling over a larger distance and have greater sensitivity to the exhumation kinematics.

[52] 6. The AHe system showed a slight sensitivity to changes in topographic relief, but in general, there is very little sensitivity in detrital age distributions to changing relief in the models we explored. There is potential for an increased response in cases where the relief change occurs over a very short time interval or within regions with a slower background denudation rate.

[53] 7. Over the range of basin areas sampled, basin size did not appear to have a significant effect on the predicted age distributions. This may not be true for very small basins, but for the basin sizes typically sampled in active orogens, we saw no effect. It should be noted, however, that the location of the basin relative to regions of variable denudation rate would be very important. In other words, the age distribution for a basin in the immediate hanging wall of a steep thrust fault would be very different from that of a basin far from a thrust and above a gentle ramp, even if the basins are of similar size.

\section{Appendix A: Thrust Model}

[54] This study uses a thrust kinematic model geometry based on geologic cross sections [Lavé and Avouac, 2000, and references therein] and tectonic maps [Searle and Godin, 2003; Bollinger et al., 2004] from central Nepal. Fault surfaces in the model are approximated as planar and kink band, fault-bend folding [Suppe, 1983] is used between fault segments of differing dip angle.

[55] The model features two thrust faults designed to simulate the basal décollement and an interior thrust (Figure 3) in the central Nepalese Himalaya. The décollement geometry follows that of the Main Himalayan Thrust (MHT) and intersects the surface near the southern end of the model as the Main Frontal Thrust (MFT). Although rarely exposed at the surface, a surface dip angle of $40^{\circ}$ is assumed for the MFT down to where it joins the MHT with a gentle dip of $4^{\circ}$. The MFT and MHT dip angles are similar to those inferred from bedding in fault-bend folds in the MFT hanging wall and plate flexure models [e.g., Lavé and Avouac, 2000]. Approximately $40 \mathrm{~km}$ north of the MFT surface trace, the MHT dip angle increases to $7^{\circ}$. Thirty kilometers further north, the detachment features a midcrustal ramp dipping at $19^{\circ}$, prior to shallowing to $10^{\circ}$. The midcrustal ramp and detachment position north of it are constrained from foliation plane dip angles [Schelling and Arita, 1991], seismic events [Pandey et al., 1995], and reflections from the INDEPTH seismic survey [Zhao et al., 1993; Brown et al., 1996]. The interior thrust fault simulates the Main Central Thrust (MCT) and has a surface dip angle of $40^{\circ}$ down to where it splays from the basal décollement with a dip angle of $10^{\circ}$. The MCT dip angle is consistent with the range of foliations measured in rocks of the GHS from western Nepal [Valdiya, 1980; DeCelles et al., 2001] and slightly steeper than measured dip of the MCT shear zone in central Nepal [Valdiya, 1980; Macfarlane et al., 1992; Hodges et al., 1996; Searle and Godin, 2003]. Along with the position of the basal décollement, these faults generate a zone of relatively rapid uplift that is coincident with the location of the highest topographic relief.

[56] Transport of material by the thrust faults occurs perpendicular to modeled fault traces assuming a constant convergence rate. The model domain is oriented such that the model y axis is parallel to the thrust vergence direction of $198^{\circ}$. The vergence direction is subparallel to observed stretching lineations [Brunel, 1986] and also aligned with modern-day geodetic measurements of Indo-Tibetan convergence [Bilham et al., 1997; Larson et al., 1999; Jouanne et al., 2004; Bettinelli et al., 2006]. Surface fault traces are approximated as linear features from the tectonic maps of Searle and Godin [2003] and Bollinger et al. [2004]. Faults strike perpendicular to vergence, parallel to the model $\mathrm{x}$ axis. Slip is partitioned among the different structures such that a constant convergence rate of $20 \mathrm{~mm} / \mathrm{y}$ is maintained between India (south of MFT) and Tibet (north of STD). This convergence rate is based on both present-day geodetic measurements from central and eastern Nepal (19 \pm $2.5 \mathrm{~mm} / \mathrm{y})$ [Bettinelli et al., 2006] and estimates of shortening over the Holocene $(21 \pm 1.5 \mathrm{~mm} / \mathrm{y})$ [Lavé and Avouac, 2000].

[57] An important point about the thrust kinematic scenario is that the reference frame has the topography fixed with the faults migrating laterally (e.g., Figures 3 and 7a). This approach is similar to the horizontal landscape advection case of Herman et al. [2007]. The rate of lateral motion is set by the convergence rate across the faults and the 
number of faults that are active inboard of the structure of interest. Rocks above the basal décollement move strictly vertically toward the model surface. The rate of vertical motion is controlled by the dip angle of a given fault hanging wall section as the faults move laterally into their present-day positions at time $0 \mathrm{Ma}$. Vertical transport is important to ensure that the cooling histories generated by tracking surface particles through the model do not contain any periods where the particles exit the model domain. When using steady state topography with a lateral component to the particle trajectories it is possible for particles to track above the model topography when their trajectory angle is shallower than the local hillslope angles. Because the thrust fault geometry utilized here has several sections with a dip angle of 10 or less degrees, we have chosen to utilize this reference frame.

[58] The faults also divide the model material properties into three regions: (1) The region subducted beneath the Himalaya and MHT, (2) the region in the MFT hanging wall and (3) the region in the MCT hanging wall. The radiogenic heat production value for material in the MCT hanging wall is spatially variable with a value of $1.9 \mu \mathrm{W} / \mathrm{m}^{3}$ proximal to the fault and $0.5 \mu \mathrm{W} / \mathrm{m}^{3} \sim 15 \mathrm{~km}$ structurally above the fault trace based on average measured values [Whipp et al., 2007] and average sedimentary rock heat production values, respectively. For the other units, the heat production value $\left(0.8 \mu \mathrm{W} / \mathrm{m}^{3}\right)$ is consistent with observed surface heat flow measurements [Roy and Rao, 2000]. All other rock thermophysical properties and boundary conditions are consistent with those used in the other kinematic model scenarios and summarized in Table 1.

[59] An additional heat source within the model is provided by frictional heating along the active fault surfaces. Frictional shear heating is calculated at all points within the model domain following the moderate friction case of Hansen and Carter [1982]. The shear stress at any point is defined as the minimum of either the pressure-dependent brittle stress or the ductile, temperature-dependent power law stress. The maximum shear stress is not allowed to exceed $50 \mathrm{MPa}$. Frictional heating becomes important in any portion of the model with significant differential velocities (e.g., fault zones) and can provide a significant amount of volumetric heat production at high slip rates. Because frictional heating is a volumetric heat source, it is combined with the radiogenic heat production of a given unit.

[60] Acknowledgments. This manuscript benefited from thoughtful discussions with J. Barnes, M. Densmore, K. Hodges, K. Huntington, F. Herman and P. van der Beek. We are grateful for detailed reviews by A. Berger, J. Rahl, an anonymous reviewer and the associate editor that significantly improved the manuscript. This work was supported by NSF grants EAR-0544954 and EAR-0724656 to T. Ehlers.

\section{References}

Amidon, W. H., D. W. Burbank, and G. E. Gehrels (2005), Construction of detrital mineral populations: Insights from mixing of U-Pb zircon ages in Himalayan rivers, Basin Res., 17(4), 463-485.

Bathe, K.-J. (1982), Finite Element Procedures in Engineering Analysis, 1st ed., 735 pp., Prentice-Hall, Englewood Cliffs, N. J.

Batt, G. E., and M. T. Brandon (2002), Lateral thinking: 2-D interpretation of thermochronology in convergent orogenic settings, Tectonophysics, 349(1-4), 185-201.

Beaumont, C., R. A. Jamieson, M. H. Nguyen, and S. Medvedev (2004), Crustal channel flows: 1 . Numerical models with applications to the tectonics of the Himalayan-Tibetan orogen, J. Geophys. Res., 109, B06406, doi:10.1029/2003JB002809.
Bernet, M., and J. I. Garver (2005), Fission-track analysis of detrital zircon, Rev. Mineral. Geochem., 58(1), 205-237.

Bernet, M., M. Zattin, J. I. Garver, M. T. Brandon, and J. A. Vance (2001), Steady-state exhumation of the European Alps, Geology, 29(1), 35-38. Bernet, M., P. van der Beek, R. Pik, P. Huyghe, J.-L. Mugnier, E. Labrin, and A. Szulc (2006), Miocene to recent exhumation of the central Himalaya determined from combined detrital zircon fission-track and $\mathrm{U} / \mathrm{Pb}$ analysis of Siwalik sediments, western Nepal, Basin Res., 18(4), 393 412, doi:10.1111/j.1365-2117.2006.00303.x.

Bettinelli, P., J.-P. Avouac, M. Flouzat, F. Jouanne, L. Bollinger, P. Willis, and G. Chitrakar (2006), Plate motion of India and interseismic strain in the Nepal Himalaya from GPS and DORIS measurements, J. Geod., 80(8), 567-589, doi:10.1007/s00190-006-0030-3.

Bilham, R., et al. (1997), GPS measurements of present-day convergence across the Nepal Himalaya, Nature, 386(6620), 61-64.

Bollinger, L., J. P. Avouac, O. Beyssac, E. J. Catlos, T. M. Harrison, M. Grove, B. Goffé, and S. Sapkota (2004), Thermal structure and exhumation history of the Lesser Himalaya in central Nepal, Tectonics, 23, TC5015, doi:10.1029/2003TC001564

Bollinger, L., P. Henry, and J. P. Avouac (2006), Mountain building in the Nepal Himalaya: Thermal and kinematic model, Earth Planet. Sci. Lett. $244(1-2), 58-71$.

Brandon, M. T., and J. A. Vance (1992), Tectonic evolution of the Cenozoic Olympic subduction complex, Washington State, as deduced from fission track ages for detrital zircons, Am. J. Sci., 292(8), 565-636.

Brandon, M. T., M. K. Roden-Tice, and J. I. Garver (1998), Late Cenozoic exhumation of the Cascadia accretionary wedge in the Olympic Mountains, northwest Washington State, Geol. Soc. Am. Bull., 110(8), $985-1009$.

Braun, J. (2002), Quantifying the effect of recent relief changes on ageelevation relationships, Earth Planet. Sci. Lett., 200(3-4), 331-343.

Braun, J. (2003), Pecube: A new finite-element code to solve the 3D heat transport equation including the effects of a time-varying, finite amplitude surface topography, Comput. Geosci., 29(6), 787-794.

Braun, J., P. van der Beek, and G. E. Batt (2006), Quantitative Thermochronology, 1st ed., 270 pp., Cambridge Univ. Press, New York.

Brewer, I. D., and D. W. Burbank (2006), Thermal and kinematic modeling of bedrock and detrital cooling ages in the central Himalaya, J. Geophys. Res., 111, B09409, doi:10.1029/2004JB003304.

Brewer, I. D., D. W. Burbank, and K. V. Hodges (2003), Modelling detrital cooling-age populations: Insights from two Himalayan catchments, Basin Res., 15(3), 305-320.

Brewer, I. D., D. W. Burbank, and K. V. Hodges (2006), Downstream development of a detrital cooling-age signal: Insights from ${ }^{40} \mathrm{Ar} /{ }^{39} \mathrm{Ar}$ muscovite thermochronology in the Nepalese Himalaya, in Tectonics, Climate, and Landscape Evolution, edited by S. D. Willett et al., Spec. Pap. Geol. Soc. Am., 398, 321-338.

Brooks, A. N., and T. J. R. Hughes (1982), Streamline upwind/PetrovGalerkin formulations for convective dominated flows with particular emphasis on the incompressible Navier-Stokes equations, Comput. Methods Appl. Mech. Eng., 32, 199-259.

Brown, L. D., W. Zhao, K. D. Nelson, M. Hauck, D. Alsdorf, A. Ross, M. Cogan, M. Clark, X. Liu, and J. Che (1996), Bright spots, structure, and magmatism in southern Tibet from INDEPTH seismic reflection profiling, Science, 274(5293), 1688-1690.

Brunel, M. (1986), Ductile thrusting in the Himalayas: Shear sense criteria and stretching lineations, Tectonics, 5(2), 247-265.

Carrapa, B., M. R. Strecker, and E. R. Sobel (2006), Cenozoic orogenic growth in the central Andes: Evidence from sedimentary rock provenance and apatite fission track thermochronology in the Fiambalá Basin, southernmost Puna Plateau margin (NW Argentina), Earth Planet. Sci. Lett., $247(1-2), 82-100$

Carslaw, H. S., and J. C. Jaeger (1959), Conduction of Heat in Solids, 3rd ed., Clarendon, Oxford, U. K.

Cerveny, P., N. Naeser, P. K. Zeitler, C. Naeser, and N. Johnson (1988), History of uplift and relief of the Himalaya during the past 18 million years: Evidence from fission-track ages of detrital zircons from sandstones of the Siwalik Group, in New Perspectives in Basin Analysis, edited by K. Kleinspehn and C. Paola, pp. 43-61, Springer, New York.

Copeland, P., and T. M. Harrison (1990), Episodic rapid uplift in the Himalaya revealed by ${ }^{40} \mathrm{Ar} /{ }^{39} \mathrm{Ar}$ analysis of detrital K-feldspar and muscovite, Bengal Fan, Geology, 18(4), 354-357.

Coutand, I., B. Carrapa, A. Deeken, A. K. Schmitt, E. R. Sobel, and M. R. Strecker (2006), Propagation of orographic barriers along an active range front: Insights from sandstone petrography and detrital apatite fissiontrack thermochronology in the intramontane Angastaco basin, NW Argentina, Basin Res., 18(1), 1-26.

Crowley, K. D., M. Cameron, and R. L. Schaefer (1991), Experimental studies of annealing of etched fission tracks in fluorapatite, Geochim. Cosmochim. Acta, 55(5), 1449-1465. 
DeCelles, P. G., D. M. Robinson, J. Quade, T. P. Ojha, C. N. Garzione, P. Copeland, and B. N. Upreti (2001), Stratigraphy, structure, and tectonic evolution of the Himalayan fold-thrust belt in western Nepal, Tectonics, 20(4), 487-509.

Densmore, M. S., T. A. Ehlers, and G. J. Woodsworth (2007), Effect of Alpine glaciation on thermochronometer age-elevation profiles, Geophys. Res. Lett., 34, L02502, doi:10.1029/2006GL028371.

Dodson, M. H. (1973), Closure temperature in cooling geochronological and petrological systems, Contrib. Mineral. Petrol., 40(3), 259-274.

Ehlers, T. A. (2005), Crustal thermal processes and the interpretation of thermochronometer data, Rev. Mineral. Geochem., 58, 315-350.

Ehlers, T. A., and K. A. Farley (2003), Apatite (U-Th)/He thermochronometry: Methods and applications to problems in tectonic and surface processes, Earth Planet. Sci. Lett., 206(1-2), 1-14.

Ehlers, T. A., et al. (2005), Computational tools for low-temperature thermochronometer interpretation, Rev. Mineral. Geochem., 58, 589-622.

Ehlers, T. A., K. A. Farley, M. E. Rusmore, and G. J. Woodsworth (2006), Apatite (U-Th)/He signal of large-magnitude accelerated glacial erosion, southwest British Columbia, Geology, 34(9), 765-768.

Farley, K. (2000), Helium diffusion from apatite: General behavior as illustrated by Durango fluorapatite, J. Geophys. Res., 105(B2), 2903-2914.

Farr, T. G., et al. (2007), The Shuttle Radar Topography Mission, Rev. Geophys., 45, RG2004, doi:10.1029/2005RG000183.

Fluteau, F. (2003), Earth dynamics and climate changes, C. R. Geosci., $335(1), 157-174$

Forster, C. B., and L. Smith (1989), The influence of groundwater flow on thermal regimes in mountainous terrain: A model study, J. Geophys. Res., 94(7), 9439-9451.

Garver, J. I., and M. T. Brandon (1994a), Erosional denudation of the British Columbia coast ranges as determined from fission-track ages of detrital zircon from the Tofino basin, Olympic Peninsula, Washington, Geol. Soc. Am. Bull., 106(11), 1398-1412.

Garver, J. I., and M. T. Brandon (1994b), Fission-track ages of detrital zircons from Cretaceous strata, southern British Columbia: Implications for the Baja BC hypothesis, Tectonics, 13(2), 401-420.

Garver, J. I., M. T. Brandon, M. K. Roden-Tice, and P. J. J. Kamp (1999), Exhumation history of orogenic highlands determined by detrital fissiontrack thermochronology, in Exhumation Processes: Normal Faulting, Ductile Flow and Erosion, edited by U. Ring et al., Geol. Soc. Spec. Publ., 154, 283-304.

Gunnell, Y. (2000), Apatite fission track thermochronology: An overview of its potential and limitations in geomorphology, Basin Res., 12(2), $115-132$.

Hames, W. E., and S. A. Bowring (1994), An empirical evaluation of the argon diffusion geometry in muscovite, Earth Planet. Sci. Lett., $124(1-4), 161-169$

Hansen, F. D., and N. L. Carter (1982), Creep of selected crustal rocks at $1000 \mathrm{MPa}$, Eos Trans. AGU, 63(18), 437.

Henry, P., X. Le Pichon, and B. Goffe (1997), Kinematic, thermal and petrological model of the Himalayas: Constraints related to metamorphism within the underthrust Indian crust and topographic elevation, Tectonophysics, 273(1-2), 31-56.

Herman, F., J. Braun, and W. J. Dunlap (2007), Tectonomorphic scenarios in the Southern Alps of New Zealand, J. Geophys. Res., 112, B04201, doi:10.1029/2004JB003472.

Hodges, K. V., R. R. Parrish, and M. P. Searle (1996), Tectonic evolution of the central Annapurna Range, Nepalese Himalayas, Tectonics, 15(6), $1264-1291$.

Hodges, K. V., K. W. Ruhl, C. W. Wobus, and M. S. Pringle (2005), ${ }^{40} \mathrm{Ar} /{ }^{39} \mathrm{Ar}$ thermochronology of detrital minerals, Rev. Mineral. Geochem., 58(1), 239-257, doi:10.2138/rmg.2005.58.9.

Huntington, K. W., T. A. Ehlers, K. V. Hodges, and D. M. Whipp Jr. (2007), Topography, exhumation pathway, age uncertainties, and the interpretation of thermochronometer data, Tectonics, 26, TC4012, doi:10.1029/ 2007 TC002108.

Jamieson, R. A., C. Beaumont, S. Medvedev, and M. H. Nguyen (2004), Crustal channel flows: 2 . Numerical models with implications for metamorphism in the Himalayan-Tibetan orogen, J. Geophys. Res., 109, B06407, doi:10.1029/2003JB002811.

Jenson, S. K., and J. O. Domingue (1988), Extracting topographic structure from digital elevation data for geographic information system analysis, Photogramm. Eng. Remote Sens., 54(11), 1593-1600.

Jiménez-Munt, I., and J. P. Platt (2006), Influence of mantle dynamics on the topographic evolution of the Tibetan Plateau: Results from numerical modeling, Tectonics, 25, TC6002, doi:10.1029/2006TC001963.

Jouanne, F., J. L. Mugnier, J. F. Gamond, P. Le Fort, M. R. Pandey, L. Bollinger, M. Flouzat, and J. P. Avouac (2004), Current shortening across the Himalayas of Nepal, Geophys. J. Int., 157(1), 1-14.
Kuhlemann, J., I. Dunkl, A. Brügel, C. Spiegel, and W. Frisch (2006), From source terrains of the Eastern Alps to the Molasse Basin: Detrital record of non-steady-state exhumation, Tectonophysics, 413(3-4), 301-316.

Larson, K. M., R. Buergmann, R. Bilham, and J. T. Freymueller (1999),

Kinematics of the India-Eurasia collision zone from GPS measurements, J. Geophys. Res., 104(1), 1077-1093.

Lavé, J., and J. P. Avouac (2000), Active folding of fluvial terraces across the Siwaliks Hills, Himalayas of central Nepal, J. Geophys. Res., 105(B3), 5735-5770.

Macfarlane, A. M., K. V. Hodges, and D. Lux (1992), A structural analysis of the main central thrust zone, Langtang National Park, central Nepal Himalaya, Geol. Soc. Am. Bull., 104(11), 1389-1402.

Mancktelow, N. S., and B. Grasemann (1997), Time-dependent effects of heat advection and topography on cooling histories during erosion, Tectonophysics, 270(3-4), 167-195.

O'Callaghan, J. F., and D. M. Mark (1984), The extraction of drainage networks from digital elevation data, Comput. Vision Graphics Image Process., 28(3), 323-344, doi:10.1016/S0734-189X(84)80011-0.

Pandey, M. R., R. P. Tandukar, J. P. Avouac, J. Lavé, and J. P. Massot (1995), Interseismic strain accumulation on the Himalayan crustal ramp (Nepal), Geophys. Res. Lett., 22(7), 751-754.

Person, M., D. Toupin, and P. Eadington (1995), One-dimensional models of groundwater flow, sediment thermal history and petroleum generation within continental rift basins, Basin Res., 7(1), 81-96.

Press, W. H., S. A. Teukolsky, W. T. Vetterling, and B. P. Flannery (1992), Numerical Recipes in C: The Art of Scientific Computing, 2 ed., Cambridge Univ. Press, Cambridge, U. K.

Rahl, J. M., T. A. Ehlers, and B. A. van der Pluijm (2007), Quantifying transient erosion of orogens with detrital thermochronology from syntectonic basin deposits, Earth Planet. Sci. Lett., 256(1-2), 147-161.

Reiners, P. W. (2007), Thermochronologic approaches to paleotopography, Rev. Mineral. Geochem., 66(1), 243-267.

Reiners, P. W., and M. T. Brandon (2006), Using thermochronology to understand orogenic erosion, Annu. Rev. Earth Planet. Sci., 34, 419-466.

Reiners, P. W., T. L. Spell, S. Nicolescu, and K. A. Zanetti (2004), Zircon (U-Th)/He thermochronometry: He diffusion and comparisons with ${ }^{40} \mathrm{Ar}{ }^{39} \mathrm{Ar}$ dating, Geochim. Cosmochim. Acta, 68(8), 1857-1887.

Reiners, P. W., T. A. Ehlers, and P. K. Zeitler (2005), Past, present, and future of thermochronology, Rev. Mineral. Geochem., 58(1), 1-18.

Reiners, P. W., S. N. Thomson, D. McPhillips, R. A. Donelick, and J. J. Roering (2007), Wildfire thermochronology and the fate and transport of apatite in hillslope and fluvial environments, J. Geophys. Res., 112, F04001, doi:10.1029/2007JF000759.

Renne, P. R., T. A. Becker, and S. M. Swapp (1990), ${ }^{40} \mathrm{Ar} /{ }^{39} \mathrm{Ar}$ laser-probe dating of detrital micas from the Montgomery Creek Formation, northern California: Clues to provenance, tectonics, and weathering processes, Geology, 18(6), 563-566.

Robbins, G. A. (1972), Radiogenic argon diffusion in muscovite under hydrothermal conditions, M.Sc. thesis, Brown Univ., Providence, R. I.

Roy, S., and R. U. M. Rao (2000), Heat flow in the Indian Shield, J. Geophys. Res., 105(11), 25,587-25,604

Ruhl, K. W., and K. V. Hodges (2005), The use of detrital mineral cooling ages to evaluate steady state assumptions in active orogens: An example from the central Nepalese Himalaya, Tectonics, 24, TC4015, doi:10.1029/ 2004TC001712.

Schaller, M., and T. A. Ehlers (2006), Limits to quantifying climate driven changes in denudation rates with cosmogenic radionuclides, Earth Planet. Sci. Lett., 248(1-2), 153-167.

Schaller, M., F. von Blanckenburg, N. Hovius, and P. W. Kubik (2001), Large-scale erosion rates from in situ-produced cosmogenic nuclides in European river sediments, Earth Planet. Sci. Lett., 188(3-4), 441-458.

Schelling, D., and K. Arita (1991), Thrust tectonics, crustal shortening, and the structure of the far-eastern Nepal Himalaya, Tectonics, 10(5), 851-862.

Searle, M. P., and L. Godin (2003), The South Tibetan detachment and the Manaslu leucogranite: A structural reinterpretation and restoration of the Annapurna-Manaslu Himalaya, Nepal, J. Geol., 111(5), 505-523.

Shuster, D. L., R. M. Flowers, and K. A. Farley (2006), The influence of natural radiation damage on helium diffusion kinetics in apatite, Earth Planet. Sci. Lett., 249(3-4), 148-161.

Smith, L., and D. S. Chapman (1983), On the thermal effects of groundwater flow: 1. Regional scale systems, J. Geophys. Res., 88(B1), $593-$ 608

Sobel, E. R., J. Chen, and R. V. Heermance (2006), Late Oligocene-early Miocene initiation of shortening in the southwestern Chinese Tian Shan Implications for Neogene shortening rate variations, Earth Planet. Sci. Lett., 247(1-2), 70-81.

Spiegel, C., J. Kuhlemann, I. Dunkl, W. Frisch, H. von Eynatten, and K. Balogh (2000), The erosion history of the Central Alps: Evidence 
from zircon fission track data of the foreland basin sediments, Terra Nova, 12(4), 163-170, doi:10.1046/j.1365-3121.2000.00289.x.

Stock, G. M., T. A. Ehlers, and K. A. Farley (2006), Where does sediment come from? Quantifying catchment erosion with detrital apatite (U-Th)/He thermochronometry, Geology, 34(9), 725-728.

Stock, J. D., and D. R. Montgomery (1996), Estimating palaeorelief from detrital mineral age ranges, Basin Res., 8(3), 317-327, doi:10.1046/ j.1365-2117.1996.00177.x.

Stüwe, K., and M. Hintermüller (2000), Topography and isotherms revisited: The influence of laterally migrating drainage divides, Earth Planet. Sci. Lett., 184(1), 287-303.

Stüwe, K., L. White, and R. Brown (1994), The influence of eroding topography on steady-state isotherms: Application to fission track analysis, Earth Planet. Sci. Lett., 124(1-4), 63-74.

Suppe, J. (1983), Geometry and kinematics of fault-bend folding, Am. J. Sci., 283(7), 684-721.

Szulc, A. G., et al. (2006), Tectonic evolution of the Himalaya constrained by detrital ${ }^{40} \mathrm{Ar}-{ }^{39} \mathrm{Ar}$, Sm-Nd and petrographic data from the Siwalik foreland basin succession, SW Nepal, Basin Res., 18(4), 375-391, doi:10.1111/j.1365-2117.2006.00307.x.

Valdiya, K. S. (1980), The two intracrustal boundary thrusts of the Himalaya, Tectonophysics, 66(4), 323-348.

van der Beek, P., J. Braun, and K. Lambeck (1999), Post-Palaeozoic uplift history of southeastern Australia revisited: Results from a process-based model of landscape evolution, Aust. J. Earth Sci., 46(2), 157-172, doi:10.1046/j.1440-0952.1999.00701.x.

van der Beek, P., X. Robert, J.-L. Mugnier, M. Bernet, P. Huyghe, and E. Labrin (2006), Late Miocene-recent exhumation of the central Himalaya and recycling in the foreland basin assessed by apatite fissiontrack thermochronology of Siwalik sediments, Nepal, Basin Res. 18(4), 413-434, doi:10.1111/j.1365-2117.2006.00305.x.
Vanderhaeghe, O., S. Medvedev, P. Fullsack, C. Beaumont, and R. A Jamieson (2003), Evolution of orogenic wedges and continental plateaux: Insights from crustal thermal-mechanical models overlying subducting mantle lithosphere, Geophys. J. Int., 153(1), 27-51.

Vermeesch, P. (2007), Quantitative geomorphology of the White Mountains (California) using detrital apatite fission track thermochronology, J. Geophys. Res., 112, F03004, doi:10.1029/2006JF000671.

Whipp, D. M., Jr., and T. A. Ehlers (2007), Influence of groundwater flow on thermochronometer-derived exhumation rates in the central Nepalese Himalaya, Geology, 35(9), 851-854, doi:10.1130/G23788A.1.

Whipp, D. M., Jr., T. A. Ehlers, A. E. Blythe, K. W. Huntington, K. V. Hodges, and D. W. Burbank (2007), Plio-Quaternary exhumation history of the central Nepalese Himalaya: 2. Thermokinematic and thermochronometer age prediction model, Tectonics, 26, TC3003, doi:10.1029/ 2006TC001991.

Zhao, W., K. D. Nelson, J. Che, J. Quo, D. Lu, C. Wu, and X. Liu (1993), Deep seismic reflection evidence for continental underthrusting beneath southern Tibet, Nature, 366(6455), 557-559, doi:10.1038/366557a0.

J. Braun, Laboratoire de Géodynamique des Chaînes Alpines, Université Joseph Fourier, F-38041 Grenoble CEDEX 9, France.

T. A. Ehlers, Institut für Geowissenschaften, Universität Tübingen, D-72074 Tübingen, Germany.

C. D. Spath, Department of Geological Sciences, University of Michigan, 2534 C. C. Little Bldg., Ann Arbor, MI 48109, USA

D. M. Whipp Jr., Department of Oceanography, Dalhousie University, Halifax, NS B3H 4J1, Canada. (dwhipp@dal.ca) 